OPEN ACCESS

Edited by:

Luis Puelles,

Universidad de Murcia, Spain

Reviewed by:

Paul Manger,

University of the Witwatersrand,

South Africa

Alino Martinez-Marcos,

Universidad de Castilla, Spain

*Correspondence:

Jeremy R. Corfield,

Department of Psychology, University

of Alberta, Biological Sciences

Building, P-217, Edmonton,

AB T6G 2E9, Canada

jr.corfield@gmail.com

Received: 08 May 2015

Accepted: 13 July 2015

Published: 29 July 2015

Citation:

Corfield JR, Price K, Iwaniuk AN,

Gutiérrez-Ibáñez C, Birkhead T

and Wylie DR (2015) Diversity in olfactory bulb size in birds reflects allometry, ecology, and phylogeny.

Front. Neuroanat. 9:102.

doi: 10.3389/fnana.2015.00102

\section{Diversity in olfactory bulb size in birds reflects allometry, ecology, and phylogeny}

\author{
Jeremy R. Corfield ${ }^{1,2 *}$, Kasandra Price ${ }^{1}$, Andrew N. Iwaniuk ${ }^{2}$, Cristian Gutiérrez-lbáñez ${ }^{3}$, \\ Tim Birkhead ${ }^{4}$ and Douglas R. Wylie ${ }^{1}$
}

\begin{abstract}
${ }^{1}$ Department of Psychology, University of Alberta, Edmonton, AB, Canada, ${ }^{2}$ Department of Neuroscience, University of Lethbridge, Lethbridge, AB, Canada, ${ }^{3}$ Lehrstuhl für Zoologie, Technische Universität München, Freising-Weihenstephan, Germany, ${ }^{4}$ Department of Animal and Plant Sciences, University of Sheffield, Sheffield, UK
\end{abstract}

The relative size of olfactory bulbs (OBs) is correlated with olfactory capabilities across vertebrates and is widely used to assess the relative importance of olfaction to a species' ecology. In birds, variations in the relative size of OBs are correlated with some behaviors; however, the factors that have led to the high level of diversity seen in OB sizes across birds are still not well understood. In this study, we use the relative size of OBs as a neuroanatomical proxy for olfactory capabilities in 135 species of birds, representing 21 orders. We examine the scaling of OBs with brain size across avian orders, determine likely ancestral states and test for correlations between OB sizes and habitat, ecology, and behavior. The size of avian OBs varied with the size of the brain and this allometric relationship was for the most part isometric, although species did deviate from this trend. Large OBs were characteristic of more basal species and in more recently derived species the OBs were small. Living and foraging in a semiaquatic environment was the strongest variable driving the evolution of large OBs in birds; olfaction may provide cues for navigation and foraging in this otherwise featureless environment. Some of the diversity in OB sizes was also undoubtedly due to differences in migratory behavior, foraging strategies and social structure. In summary, relative OB size in birds reflect allometry, phylogeny and behavior in ways that parallel that of other vertebrate classes. This provides comparative evidence that supports recent experimental studies into avian olfaction and suggests that olfaction is an important sensory modality for all avian species.

Keywords: olfactory bulb, comparative neuroanatomy, olfaction, sensory ecology, avian ecology

\section{Introduction}

The importance of olfaction to bird ecology and behavior has largely been underplayed. In fact, early ornithologists debated if birds had a sense of smell at all (Bang and Cobb, 1968; Roper, 1999). However, recent interest in avian olfaction is demonstrating that birds have a fully functional olfactory system and some species rely heavily on their sense of smell for many tasks. (see reviews Roper, 1999; Hagelin, 2007; Caro and Balthazart, 2010; Castro et al., 2010). Birds use olfaction in a wide range of contexts that parallel that of mammals and other vertebrates, including: foraging (Stager, 1964; Wenzel, 1968; Grubb, 1972), predator avoidance 
(Amo et al., 2008, 2011; Roth et al., 2008; Zidar and Lovlie, 2012; Stanbury and Briskie, 2015), advertisement and mate selection (Balthazart and Schoffeniels, 1979; Balthazart and Taziaux, 2009; Caro and Balthazart, 2010; Amo et al., 2012; Whittaker et al., 2013; Caro et al., 2015), to discriminate conspecifics, consubspecifics, and sexes (Mihailova et al., 2014) and even for territorial scent marking (Castro et al., 2010). To support these behaviors, sensitivities to odors in birds are comparable to that of some mammals (Stattleman et al., 1975; Snyder and Peterson, 1979; Smith and Paselk, 1986; Walker et al., 1986; Waldvogel, 1989; Clark et al., 1993).

The primary neural structures of the vertebrate forebrain involved in olfaction are the multi-layered olfactory bulbs (OBs). OBs vary considerable in relative size across vertebrates and in mammals and fishes this variation is not driven by the size of the rest of the brain; there is a high level of allometric independence from the rest of the brain (Finlay and Darlington, 1995; Finlay et al., 2001; Reep et al., 2007; Gonzalez-Voyer et al., 2009; Yopak et al., 2010, 2015). Much of this variation is correlated with an animal's behavioral ecology, especially those behaviors that require improved olfactory sensitivities. For example, larger $\mathrm{OBs}$ are found in nocturnal primates and insectivores, reflecting their increased reliance on olfaction for foraging and social interactions when vision is constrained under low light levels (Barton et al., 1995). In birds, differences in foraging ecology, habitat, nesting strategy, diet, and activity patterns have been correlated with variations in OB sizes (Bang, 1971; Bang and Wenzel, 1985; Healy and Guilford, 1990; Hagelin, 2004; Hammock, 2005; Mackay-Sim and Royet, 2006; Buschhuter et al., 2008; Corfield et al., 2014). This strong correlation between olfactory mediated behaviors and relative OB sizes across vertebrates has led to the suggestion that the size of OBs is a functional adaptation rather than a phylogenetic consequence (e.g., Healy and Guilford, 1990; Gittleman, 1991; Barton et al., 1995; Corfield et al., 2014; Yopak et al., 2015), although this has yet to be tested on a large scale among vertebrates (but see Yopak et al., 2010).

Although it is clear that variations in OB sizes in birds can be attributed to aspects of their behavioral ecology, there is also a trend for more basal species, such as Apterygiformes (kiwi), and Anseriformes (ducks), to have larger OBs (Bang and Cobb, 1968; Wenzel, 1971). This led to the conclusion that modern birds (neornithines) were descended from ancestors that had a heavy reliance on olfaction, and a shift away from olfaction resulted from visual and vestibular sensory enhancements associated with flight (Wenzel, 1971; Alonso et al., 2004; Milner and Walsh, 2009). Indeed, recent evidence suggests that OB sizes initially increased during non-avian maniraptoriform evolution and then further increased during basal bird and early neornithine evolution (Zelenitsky et al., 2011).

Together with phylogeny, ecology, and behavior, the rules that govern the scaling of OBs with brain/body size are also likely to be influencing the relative sizes of OBs. Indeed, the patterns of neural scaling can be an important determinant of the size of specific brain regions (Herculano-Houzel, 2009; Ribeiro et al., 2014; Corfield et al., 2015). Therefore, it is clear that many factors, including, but not limited to, phylogeny, ecology/behavior, and neural scaling patterns are driving the diversity in $\mathrm{OB}$ sizes in birds. However, the degree in which each of these variables has shaped the evolution of olfaction in birds in currently unknown.

Variations in the size of the OBs were first described in birds by Bang and Cobb (1968), who produced a data set of $\mathrm{OB}$ ratio percentages (OB diameter/hemisphere diameter) in 108 species, which was obtained by measuring the greatest diameter of the OBs and hemispheres. They showed that the OB ratios ranged from over 37 in snow petrels (Pagodroma nivea) to less than 5 in some Passeriformes, providing the first evidence that species difference in the size of OBs was functionally significant. However, as noted by Corfield et al. (2014) and Caro et al. (2015), the methods used in this study do not account for species differences in brain morphology and are unlikely to provide an accurate estimate of OB size. Bang and Cobb (1968) also note that there were difficulties and inaccuracies associated with measuring the "longest diameter" of organs that are not spherical. Although the OB measurements of Bang and Cobb (1968) have been used in several studies (Healy and Guilford, 1990; Zelenitsky et al., 2011), we developed a new data set using measurements from histological sections, allowing for a more accurate examination of $\mathrm{OB}$ sizes across birds and for more species.

Using this new data set, we examine the size of OBs in 135 species of birds, representing 21 different orders. We determine the scaling of the OBs with brain size, the effects of phylogeny, and diversification on $\mathrm{OB}$ sizes across a phylogeny and test for correlations of $\mathrm{OB}$ sizes with different habitats, ecology, and behavior. Variables such as migratory behavior and foraging strategies (habitat type and diet) were used because there is evidence that these behaviors are mediated by olfaction (e.g. Wenzel, 1968, 1971; Papi, 1982; Graves, 1992; Wallraff, 2003; Bonadonna et al., 2006). There is also growing evidence that olfaction is widely used in social communication and reproductive activities (see reviews Balthazart and Taziaux, 2009; Caro et al., 2015), therefore species were grouped by their mating system and social structure (group size, see below). With this suite of analyses, we demonstrate what factors have led to the diversity of $\mathrm{OB}$ sizes in extant birds and provide novel insight into the potential importance of olfaction in different avian lineages.

\section{Materials and Methods}

\section{Specimens}

Data on the size of olfactory bulbs was compiled from a total of 274 brains from 135 species of birds, which represent 21 orders. Species were grouped into orders based on Hackett et al. (2008). Specimens were obtained post-mortem from conservation authorities, wildlife veterinarians, and museum staff. Since animals were not killed to conduct this study, no university ethics approvals were required for this research. Additional data were compiled from the studies of Ebinger and Lohmer (1987), Boire (1989), Rehkamper et al. (1991), Alma and Bee De Speroni (1992), Carezzano and Bee De Speroni (1995), Fernandez et al. (1997), Pistone et al. (2002), Mehlhorn et al. (2010), Corfield et al. (2011, 2012b, 2014, 2015), Gsell (2012), Cunningham et al. (2013), and Gutierrez-Ibanez et al. 
(2014). Whole brain, telencephalon, and OBs sizes are included in Supplemental Table S1, which also includes the source, common names, and order for each species.

Because data is combined from multiple studies, each using different fixation protocols, it is likely that some differential shrinkage between studies has occurred. To minimize this effect, we used only the relative size of a brain structure, as all regions of a brain likely shrink by the same amount (Corfield et al., 2012a, 2014). Therefore, although the brain may have shrunk more in one study compared to another, the relative size of one structure to another within each brain will likely be comparable between studies. Coefficients of variation $(\mathrm{CV})$ values, based on the ratio of $\log \mathrm{OB}$ volume to log telencephalon volume, also suggested that within species variation was low, ranging from 0.85 to $9.70 \%$ ( $n=6$ species). For example, in mallards (Anas platyrhynchos, $n=4)$ the standard deviation was $6.5 \%$ of the mean, and in ring-necked pheasant (Phasianus colchicus, $n=4$ ) and turkey (Meleagris gallopavo, $n=4$ ) the value was 6.0. The $\mathrm{CV}$ values for these three species were calculated included measurements from Boire (1989), also suggesting that the variations between studies was low. Further, Corfield et al. (2012a) found that for most species, the variation in $\mathrm{OB}$ measurements among studies is low and for species represented by more than one specimen, the amount of intraspecific variation was low.

\section{Brain Processing}

All specimens measured for this study were immersion-fixed in $4 \%$ paraformaldehyde (PFA) in $0.1 \mathrm{M}$ phosphate buffer saline (PBS) for at least 1 week and then cryoprotected in a 30\% sucrose solution in PBS until they sunk. Specimens were embedded in a $15 \%$ gelatin and $30 \%$ sucrose solution, placed into $4 \%$ PFA overnight, and then into $20 \%$ sucrose until the block sank. The embedded brains were sectioned on a sliding freezing microtome at a thickness of $40 \mu \mathrm{m}$ in the sagittal or coronal plane and sections collected in PBS with $0.01 \%$ sodium azide. Every second section was mounted onto gelatinized slides, dehydrated through a graded ethanol series, cleared in Hemo-D, stained with thionin acetate (Sigma-Aldrich) and coverslipped with Permount histological mounting medium (Fisher Scientific).

\section{D Modeling}

For species shown in Figure 1, fiducial points were added to the gelatin block during the embedding process to align sections for $3 \mathrm{D}$ reconstructions (see details in Corfield et al., 2012b). In two species, Amazilia tzacatl and Scolopax rusticola, sections were aligned based on a template created from sections with fiducial points. Images of brain sections were aligned using the Alignslice module in AMIRA (v. 5.4.2, Visage Imaging, San Diego, CA, USA). To create $3 \mathrm{D}$ reconstructions, the LabelField module in AMIRA was used to segment out each brain region and the SurfaceGen module to create a $3 \mathrm{D}$ representation of the brain and OBs.

\section{Volumetric Measurements and Analysis}

Images of Nissl sections were taken using a Retiga EXi FAST Cooled Mono 12-bit camera (Qimaging, Burnaby, BC, Canada) attached to a compound light microscope (Leica
DMRE, Richmond Hill, ON, Canada) at $2.5 \times$ magnification. Brain, telencephalon, "brainrest" (which includes the brainstem, midbrain, thalamus, and cerebellum) and $\mathrm{OB}$ volumes were obtained directly from these images using Image $(1.47 \mathrm{v}$, National Institutes of Health, USA). The border of the OB was defined as the inner edge of the periventricular layer and the outer edge of the olfactory fila and excluded the olfactory nerve. To obtain the volume of the OB, the cross-sectional area for each section was added to obtain a single area, which was then multiplied by the slice thickness $(40 \mu \mathrm{m})$ and sampling interval. The number of sections containing the $\mathrm{OB}$ ranged from six sections (spanning $240 \mu \mathrm{m}$ ) in hummingbirds (Trochiliformes) to 44 in kiwi (spanning $1760 \mu \mathrm{m}$ ). To examine scaling relationships, we plotted the $\log _{10}$-transformed volume of the OBs against the $\log _{10}$-transformed; brain volume minus the volume of the OBs; telencephalon volume minus the volume of the OBs; and the brainrest volume.

Because phylogeny can significantly affect brain evolution (Harvey and Pagel, 1991), we first tested for phylogenetic signal using the phytools package in R (Revell, 2009; R Core Team, 2013) using Blomberg's K (Blomberg et al., 2003). We found a significant phylogenetic signal for all variables (randomization test, $p>0.001$ for all variables); therefore, we used analyses that accounted for phylogenetic effects. Phylogenetic trees were constructed based on Hackett et al. (2008) using Mesquite (v 2.75, Maddison and Maddison, 2011). Additional resolution within orders were acquired for Passeriformes (Johansson et al., 2008), Corvidae (Ericson et al., 2005), Psittaciformes (Wright et al., 2008), Anseriformes (Donne-Gousse et al., 2002), Galliformes (Wang et al., 2013), Charadriiformes (Mayr, 2011), and Tinamiformes (Bertelli and Porzecanski, 2004).

Allometric equations were calculated using phylogenetic generalized least squares (PGLS) to account for phylogenetic relatedness (Garland and Ives, 2000; Garland et al., 2005). We applied three models of evolutionary change using the ape (Paradis et al., 2004) and nlme (Pinheiro et al., 2014), packages in R: Brownian motion (BM), Pagel's lambda (Pagel, 1999) and Ornstein-Uhlenbeck (OU) (Lavin et al., 2008; Swanson and Garland, 2009). Because the phylogeny was constructed from multiple sources, branch lengths were all set at 1 , which provided adequately standardized branch lengths when checked using the procedures outlined in Garland et al. (1992). Unresolved nodes were treated as soft polytomies, with branch lengths between internal nodes set to zero (Purvis and Garland, 1993). Allometric equations were based on standard statistics, and three evolutionary models were calculated for: (1) OB volume against brain volume minus $\mathrm{OB}$ volume; (2) $\mathrm{OB}$ volume against telencephalon volume minus $\mathrm{OB}$ volume, and (3) $\mathrm{OB}$ volume against brain volume minus telencephalon (brainrest). In order to test for differences in the relative size of the $\mathrm{OB}$ among avian orders, we also ran regression models that included order as a covariate. Akaike Information Criterion (AIC) was used to determine which model best fit the data, with the lowest AIC considered to be the best fit (Lavin et al., 2008). Models with AIC values that differed by less than 2 units can also be considered as having substantial support (Burnham and Anderson, 2002; Duncan et al., 2007). 
A

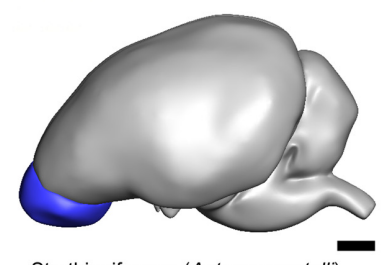

Struthioniformes (Apteryx mantelli)

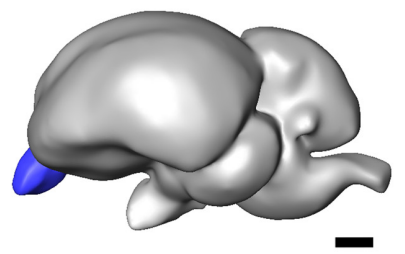

Gruiformes (Porphyrio porphyrio)

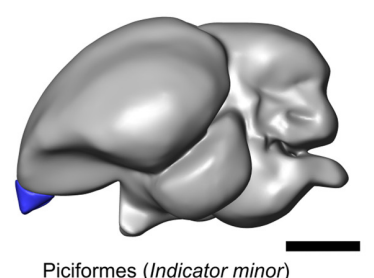

Piciformes (Indicator minor)

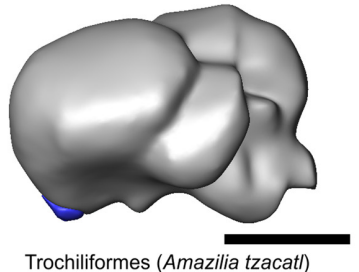

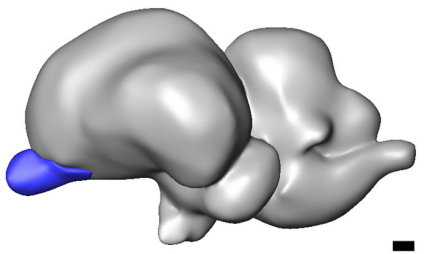

Struthioniformes (Dromaius novaehollandiae)

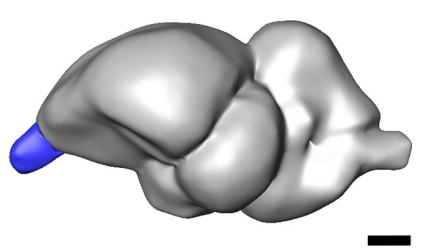

Tinamiformes (Tinamus major)

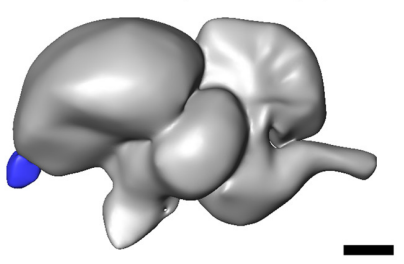

Columbiformes (Columba livia)

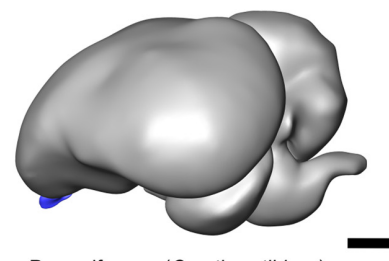

Passeriformes (Cracticus tibicen)

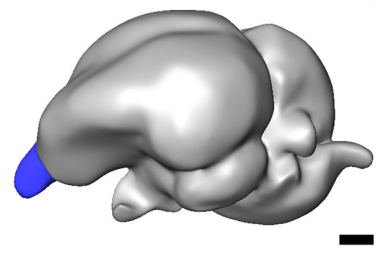

Anseriformes (Tadorna variegata)

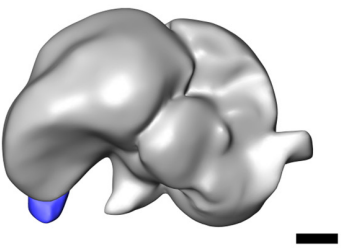

Charadriiformes (Scolopax rusticola)

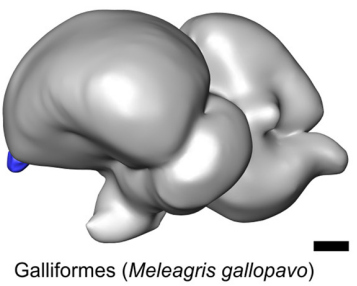

Galliformes (Meleagris gallopavo)

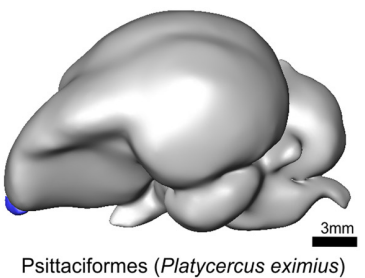

B
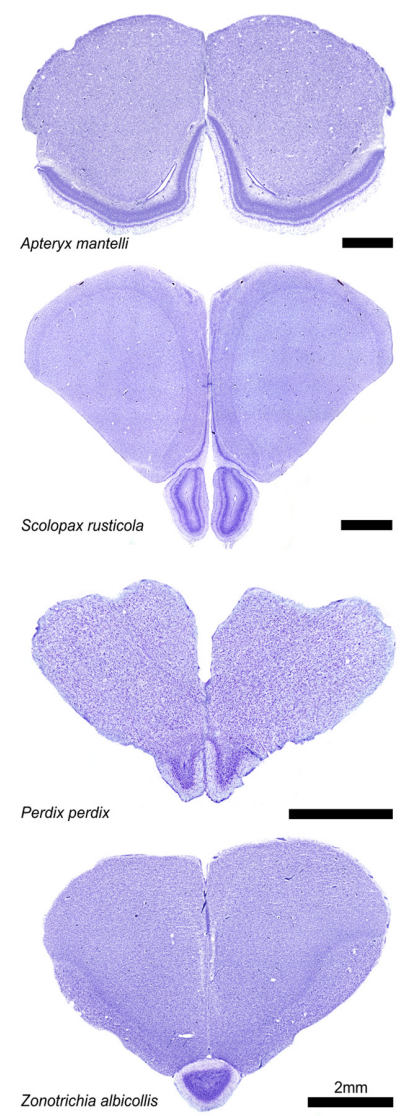

FIGURE 1 | Gross morphology of the olfactory bulbs (OBs) in birds. (A) Lateral view of 3D models of 12 representative avian species. Blue denotes the OBs and models are organized from largest to smallest. Scale

bar $=3 \mathrm{~mm}$. (B) Coronal Nissl stained sections showing the OBs in four representative avian species and illustrating the cytoarchitectural and cross species variation. Scale bar $=2 \mathrm{~mm}$.

To examine the scaling of the OBs with brain, telencephalon, and brainrest, we also performed generalized least squares (GLS) regressions using species means in JMP v. 10 (SAS Institute). Although GLS regression does not account for the relatedness of species and treats species values as statistically independent data points, it does allow for general scaling rules across birds to be established similar to those used extensively in mammals (Herculano-Houzel et al., 2014). GLS also provides bases from which to determine how phylogenetic relationships affect the scaling of OBs.

\section{Ecological Categorization}

Ecological data was obtained for 135 species of birds and categorized on the basis of diet, migratory behavior, habitat, mating system, social structure, and flying capabilities (Cramp, 1994; del Hoyo et al., 2014).

\section{Migratory Behavior}

It has long been thought that olfaction plays some role in navigation and homing in birds, whereby birds deduce positional information from airborne odors carried by winds to find their way home (e.g., Papi, 1976, 1982; Wallraff, 2004, 2013). Navigation by olfactory cues has been shown in many species ranging from swifts, Apus apus (Fiaschi et al., 1974), starlings, Sturnus vulgaris (Wallraff et al., 1995), catbirds Dumetella carolinensis (Holland et al., 2009), pigeons Columba livia (Papi, 1976; Wiltschko and Wiltschko, 1992; Benvenuti and Ranvaud, 2004) and many seabirds (Gagliardo et al., 2013). However, there is some skepticism with respect to olfactory mediated navigation (e.g., Gould, 2009; Jorge et al., 2009, 2010; Wiltschko, 2012; Blaser et al., 2013; Phillips and Jorge, 2014; Wallraff, 2014), therefore determining if migration behavior correlates with relatively large OBs might shed some light on this argument. Larger OBs might give migratory species an improved ability to decode and map patterns of odorants, allowing for example, locations to be mapped to olfactory space, an aspect that is crucial for both short and long-distance navigation (Jacobs, 2012). Migratory behavior was grouped into three categories; (1) those that have regular seasonal migration, normally traveling 1000 s of kilometers between breeding and wintering grounds. (2) those that have more localized movement within an area, normally driven by seasonal 
changes in food supply. (3) those that are sedentary, residing in a single location and normally maintaining a year round territory.

\section{Social Communication and Reproductive Behaviors}

Studies demonstrating the role of olfaction in sociality and reproduction in birds are growing and it is clear that in some species it plays an important role (see review, Balthazart and Taziaux, 2009; Caro and Balthazart, 2010; Caro et al., 2015). For example; mate recognition has been demonstrated in Antarctic prions (Pachyptila desolata, Bonadonna and Nevitt, 2004), olfactory cues have been linked to reproductive behaviors in mallards (Anas platyrhynchos, Balthazart and Schoffeniels, 1979; Caro and Balthazart, 2010) and the distinctive tangerine odor of crested auklets (Aethia cristatella) has been suggested to play a social and reproductive role (Hagelin et al., 2003). As categories for social communication and reproductive behaviors we used: (1) social mating system, where birds were categorized as monogamous (one mate during their lifetime) or polygamous (more than two mates), and (2) social complexity, where birds were organized by group size, which is often used as a measure of social complexity (Dunbar, 1995; Burish et al., 2004; Lehmann and Dunbar, 2009). For social complexity, we categorized birds as: solitary ( 1 to 3 birds), covey (5 to 50 birds) or colonial (100s to 1000s of birds) following the scheme of Burish et al. (2004). However, unlike Burish et al. (2004), we including breedingground gatherings in our assessment of group size; for example if a species is solitary for most of its life, but comes together to breed in groups of $\sim 1000$, this species would be categorized as colonial. In species that gather in large groups or colonies, such as most shorebirds and seabirds, chemosignals could be utilized for many behaviors including territoriality, attraction, individual, species, and kin recognition, hierarchical status, and mate-choice (see reviews Balthazart and Taziaux, 2009; Caro and Balthazart, 2010; Caro et al., 2015), therefore enhanced olfactory capabilities might be expected in these species.

\section{Foraging Strategies}

Olfaction is widely accepted to play a significant role in foraging and has been reported in a number of birds, including kiwi (Apteryx australis, Wenzel, 1968, 1971), and vultures (Stager, 1964; Graves, 1992), and is also well documented in seabirds (Grubb, 1972; Hutchison and Wenzel, 1980; Lequette et al., 1989; Verheyden and Jouventin, 1994). We split foraging strategies into two categories; diet and habitat type. For diet, species were categorized into those that are carnivores, herbivores, insectivores, and piscivores. Habitat type was broadly defined as either species that were (1) semi-aquatic, meaning they utilized the ocean, rivers, lakes, or wetlands for foraging, (2) aquatic, meaning they spent most of their life in water, such as penguins, and (3) terrestrial, meaning that they live and forage almost exclusively on land.

\section{Flying Capabilities}

In a recent study done by Corfield et al. (2014) some of the largest relative $\mathrm{OB}$ sizes were found in kiwi and emu (Dromaius novaehollandiae), both flightless and also two gruiform species
(Fulica armillata and Porphyrio porphyrio melanotus), which have poor flying abilities. This putative correlation may suggest that enhanced olfactory capabilities have evolved in species that spend their entire life on or near the ground, although this has yet to be tested on a large scale. We therefore categorized species by their flying capabilities; (1) those that are flightless, having wings that are incapable of flight, (2) those with poor flight, spending most of the time on the ground, but are capable of short bursts of flight if disturbed or to reach roosts, (3) those that are aerial and are capable of maintained flight.

To examine whether relative $\mathrm{OB}$ size varied significantly with the behavioral categories, we used PGLS models with the categories as covariates. For simplicity, we only show Pagel's (1999) transformation as the evolutionary model, but the results were qualitatively the same when we applied other evolutionary models. As before, AIC was used to determine which model best fit the data. Additionally, we used likelihood ratio tests to compare the fit of each model against the null model (OB vs. brain volume).

\section{Visual and Tactile Brain Regions}

It is clear from studies in fish and mammals that brain regions compete with one another for their proportion of total brain mass (Jerison, 1973; Yopak et al., 2010). Although this has yet to be tested in birds, it is possible that variation in OB sizes could be as a result of the relative size of other sensory systems. For example, owls have a massive thalamofugal visual pathway and large auditory nuclei, which may have resulted in their relativity small OBs, optic tectum (TeO) and principal sensory nucleus of the trigeminal nerve (PrV) (Kubke et al., 2004; Iwaniuk et al., 2006, 2008; Martin et al., 2007; Gutierrez-Ibanez et al., 2009). Therefore, we measured the volumes of the PrV, and TeO, which receive projections from the beak (Dubbeldam, 1990) and retina (Hunt and Webster, 1975), respectively, to determine whether relative $\mathrm{OB}$ sizes are correlated with the relative size of either of these brain regions. Measurements were obtained from the same specimens that $\mathrm{OB}$ volumes were obtained and using the same method as outline above. We also included data from GutierrezIbanez et al. (2009, 2014) and Cunningham et al. (2013), giving us data from 91 species in total. Phylogenetically corrected residual analysis was carried out for both $\mathrm{PrV}$ and $\mathrm{TeO}$ as above and species with positive residuals were categorized as having a large brain region and those with negative as small.

\section{Trait Mapping}

We use the contmap function of the phytools $\mathrm{R}$ package (Revell, 2012) to visualize changes in the relative size of OBs through phylogeny. The contmap function maps a continuous trait, in this case the relative size of $\mathrm{OB}$, onto the phylogeny by estimating the ancestral states at the internal nodes using maximum likelihood and interpolating the states along each edge using Eq. 2 of Felsenstein (1985; Revell, 2013). The relative size of OBs are expressed as the residuals of the best fitting PGLS model. Although we created plots for all three scaling variables, they were all nearly identical and species values were all strongly correlated with 
one another. Therefore only the plot for brain volume is shown.

We also took the order averages of the relative size (expressed as the residuals of the best fitting PGLS model of each area against brain volume) of each sensory area (OB, $\mathrm{PrV}$, and $\mathrm{TeO})$ and used the fancyTree function of phytools (Revell, 2012) to map each trait onto the phylogeny, as above. We also used this package to plot one trait against the other, while mapping the phylogenetic relationship of orders. Phylogenetic relationships are projected into the Cartesian space and are indicated by line connections. For example, $\mathrm{OB}$ was plotted against the $\mathrm{TeO}$, with lines collecting closely related species, such as galliforms and Anseriformes.

\section{Results}

\section{OB Morphology}

There was considerable morphological variation in the relative size and shape of OBs within and across orders (Figure 1). Perhaps the most divergent shape of the OBs is that of kiwi; the OBs extend over the majority of the rostral telencephalon and form an extensive cortex-like sheet (Figure 1, Corfield et al., 2014). A stalk-like or 'pedunculated' structure is typical of all other birds examined, although the shape and anatomical location differs among species, together with obvious relative size differences (see below). The telencephalon of the Eurasian woodcock (Scolopax rusticola), for example, is pitched forward, likely due to their eyes being set far back in their head (Martin, 1994), resulting in a more ventrally placed OB. In all 33 songbird species examined, including corvids, the OBs are fused. An example of the OBs of the white-throated sparrow (Zonotrichia albicollis) is shown in Figure 1. The laminar organization of OBs was highly conserved across the species examined in this study, including kiwi (Figure 1B). The external plexiform, mitral cell, internal plexiform, granule cell, and periventricular layers were all visible in Nissl sections, although there were obvious differences in regards to the relative thickness and cell density of layers.

\section{Scaling of the OB with Brain Size}

Brain volumes ranged from $103.68 \mathrm{~mm}^{3}$ in pygmy swiftlets (Collocalia troglodytes) to $27006.26 \mathrm{~mm}^{3}$ in ostriches (Struthio camelus), constituting a 260 -fold increase, whereas the volume of the OBs varied from $0.06 \mathrm{~mm}^{3}$ in spotted pardalotes (Pardalotus punctatus) to $217.63 \mathrm{~mm}^{3}$ in emus, constituting a 3627-fold increase in size. When accounting for phylogeny, the volume of the OBs significantly varied as a function of brain, telencephalon, and brainrest volumes ( $p$ 's $<0.001$, $F^{\prime}$ s $=3.98-39.00$, Figures 2A,C,E). The OBs scaled with the telencephalon with negative allometry $(\alpha=0.846 \pm 0.070$, Figure 2C), suggesting that the $\mathrm{OBs}$ gain volume slower than the telencephalon does. The exponent was closer to isometry for the brain $(\alpha=0.934 \pm 0.076$, Figure $2 \mathrm{~A})$ and brainrest $(\alpha=0.948 \pm 0.088$, Figure 2E), indicative of a linear relationship where the OBs gain mass at the same rate as does the brainrest and brain as a whole. For GLS regressions, the volume of the
OBs also significantly varied as a function of brain, telencephalon and brainrest volumes ( $p$ 's $<0.001, F$ 's $=184.940-237.581$, $\mathrm{df}=1,134)$, and scaled with positive allometry (Figures $2 \mathrm{~A}, \mathrm{C}, \mathbf{E})$. The OBs scaled with brain volume $(\alpha=1.170 \pm 0.072$, $\mathrm{CI}=1.011-1.324$, Figure 2A) and brainrest $(\alpha=1.277 \pm 0.076$, $\mathrm{CI}=1.126-1.458$, Figure 2E) with positive allometry, suggesting that the OBs gain volume faster than does the brainrest and brain as a whole. The OBs scaled with the telencephalon close to isometry ( $\alpha=1.038 \pm 0.069, \mathrm{CI}=0.883-1.183$, Figure 2C). Compared to a GLS approach, PGLS suggests that the OBs scaled with all three variables at a slower rate, with the telencephalon scaling at the slowest rate. This suggests that phylogenetic relationships among birds are effecting how the OBs scale with brain size.

The $r^{2}$ values for the OBs against brain, telencephalon, and brainrest were $0.621,0.581$, and 0.64 , respectively, suggesting that some of variation in the volume of OBs cannot be explained by brain, telencephalon, or brainrest volume.

\section{Scaling of the OB Within Orders}

Scaling of the OBs was examined individually for ducks (Anseriformes), shorebirds (Charadriiformes), pigeons (Columbiformes), galliforms, songbirds (Passeriformes, with and without corvids and Cracticus tibicen), honey guides, woodpeckers, barbets, and toucan (Piciformes), parrots (Psittaciformes), and ratites + tinamous (Struthioniformes + Tinamiformes) (Table 1). The volume of the OBs varied significantly as a function of the brain volume in all orders $(p<0.05)$ except pigeons $(p=0.094, F=4.776$, $\mathrm{df}=1,5)$ and shorebirds $(p=0.164, F=2.350, \mathrm{df}=1,9$, $\left.r^{2}=0.227\right)$. In shorebirds, little of the variation in $\mathrm{OB}$ volumes could be explained by brain volume $\left(r^{2}=0.227\right)$, whereas in honey guides, woodpeckers, barbets, and toucan, most of the variation could be explained by brain volume $\left(r^{2}=0.806\right)$.

In most orders, the OBs scaled with brain, telencephalon, and brainrest volume isometrically, more so than the relationship across all species (Table 1). There were, however, some exceptions. In ducks, the OBs scale with negative allometry (Brain; $\alpha=0.790 \pm 0.135$, Tel; $\alpha=0.615 \pm 0.142$, Brainrest; $\alpha=0.787 \pm 0.148$ ), suggesting that the OBs gain volume slower than the brain (especially the telencephalon) compared to that of other species. When all songbirds are included in the regression analysis, the OBs scale with brain, telencephalon and brainrest volume with negative allometry (Brain; $\alpha=0.680 \pm 0.174$, Tel; $\alpha=0.646 \pm 0.159$, Brainrest; $\alpha=0.755 \pm 0.205$, Figure 3, Table 1). However, when corvids and the Australian magpie (Cracticus tibicen) are removed from the analysis, the exponents shift to an isometric relationship (Brain; $\alpha=1.261 \pm 0.315$, Tel; $\alpha=1.254 \pm 0.286$, Brainrest; $\alpha=1.161 \pm 0.356)$.

\section{Species and Order Variations in OB Size}

Nearly all bird species fall inside of the $95 \%$ prediction intervals, suggesting that the OBs scale with brain size in a reasonably predictable manner across birds (Figure 2). The only exceptions to this were kiwi, with hypertrophied OBs when regressed against brainrest, and some songbirds, which have hypotrophied OBs. 

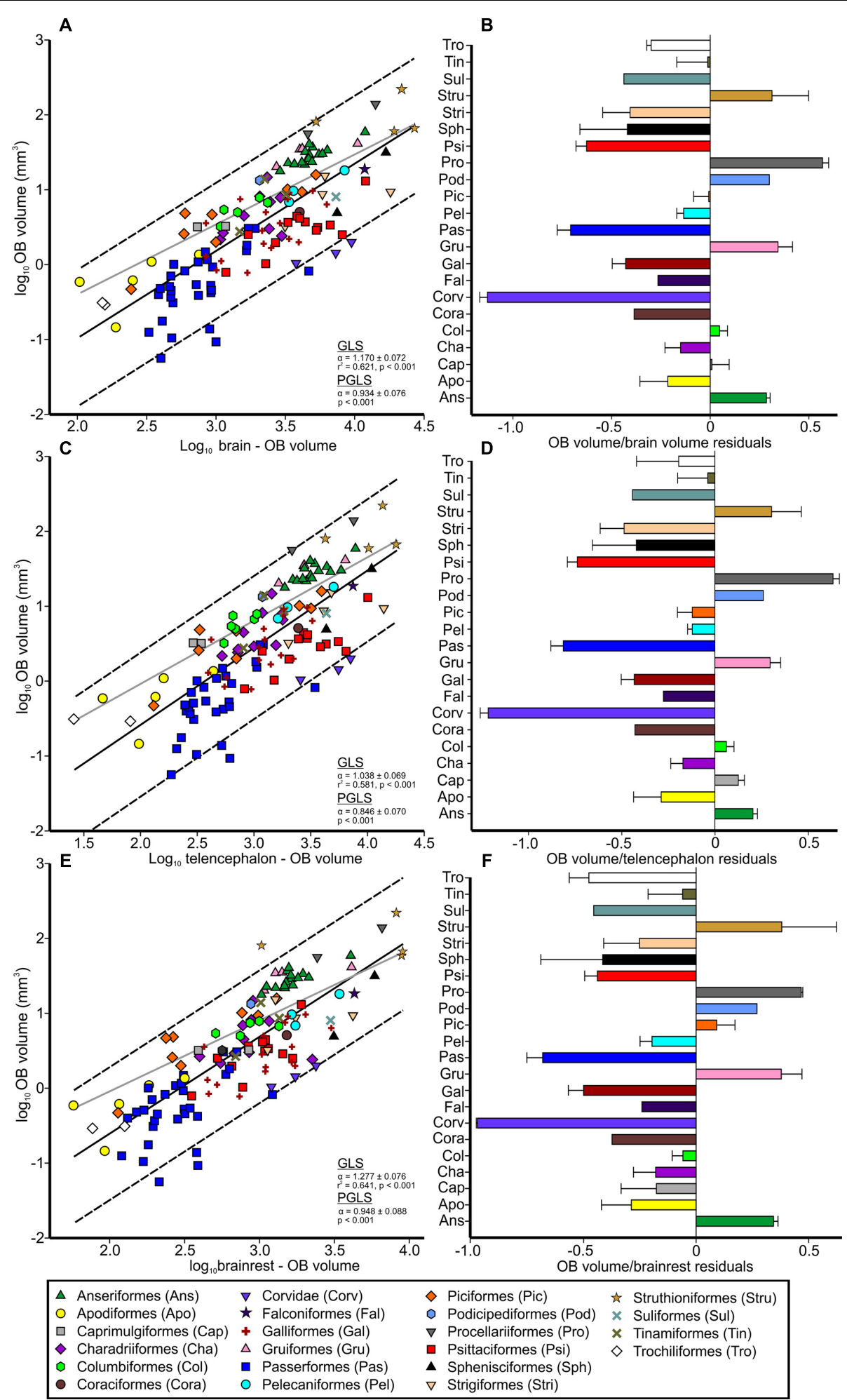

FIGURE 2 | Relative size of the OBs in birds. Scatterplots of the log-transformed volume of the OBs plotted as a function of either: (A) the log-transformed brain volume minus the volume of the OBs, (C) the log-transformed telencephalon volume minus the volume of the OBs or (E); the brainrest (brainstem, cerebellum, and thalamus) volume. The solid lines indicate the results from the generalized least-squares (GLS) regression, the broken lines the 95\% prediction intervals and the gray lines the results from the phylogenetic generalized least squares (PGLS) model. Symbols denote order as presented in legend. Bar graphs show the size of OBs relative to: (B); the brain, (D); the telencephalon; and (F) the brainrest, with bars representing the order means (with $\mathrm{SD}$ ) of the residuals derived from the respective regressions. 
Indeed, the residuals for the songbirds were the smallest of all species examined in this study (Figures 2B,D,F). Parrots, penguins, owls, and galliforms were also characterized by small OBs whereas ducks, seabirds, rails and ratites by large OBs (Figure 2).

To further examine how phylogeny relates to variations in $\mathrm{OB}$ sizes, we plotted the residuals of $\mathrm{OB}$ vs. brain (as a continuous character) onto a phylogeny and determined likely ancestral states (Figure 3). In all ratites, the OBs have increased in size from the predicted ancestral condition, with a further increase in the ancestor of kiwi and emu (0.47). The OBs in the three species of tinamou varied from large in the great tinamou (Tinamous major, 0.28), to small in Darwin's Nothura (Nothura darwinii, -0.22). The OBs of all duck species have increased in size (0.19-0.45), however, OBs in the closely related galliforms are small and are reduced in size (-0.86$0.09)$ compared to the predicted ancestral condition. Rails and seabirds are characterized by some of the largest OBs found in this study (0.37-0.60), with pigeons, honey guides (Indicator sp., especially I. variegatus), Eurasian woodcock (Scolopax rusticola) and white-tufted grebe (Rollandia rolland) all characterized by moderately large OBs. Songbirds and parrots were clearly characterized by small OBs, with many instances where specific species have undergone an even further reduction in OB sizes. For example; Eurasian bullfinch (Pyrrhula pyrrhula), whitebreasted nuthatch (Sitta carolinensis), Carolina chickadee (Poecile carolinensis) and spotted pardalote have some of the smallest relative $\mathrm{OB}$ sizes found in this study $(-1.35,-1.57,-1.22$, and 1.41 , respectively). It appears that the common ancestor of corvids (Corvus sp. and Garrulus glandarius), Australian magpies and magpie-larks (Grallina cyanoleuca) had small OBs (-0.96), with the slightly larger OBs of magpie-larks (-0.48) likely a derived trait.

\section{Variation in OB Size in Relation to Ecology}

Relative OB sizes were analyzed, while taking into consideration phylogenetic relationships, to determine if variations in size could be correlated with specific ecological variables (Figure 4). The OB residuals for species that inhabited a semi-aquatic (median 0.25 , mean 0.18 ) were mostly positive whereas the residuals in aquatic (median -0.44 , mean -0.43 ) and terrestrial (median -0.41, mean -0.40) species were mostly negative. A statistically significant effect was found for habitat $(p=0.008$, $\lambda=0.922$ ), suggesting that semi-aquatic species have larger OBs than both aquatic and terrestrial species. The OB residuals for species with a large $\operatorname{PrV}$ (median 0.30, mean 0.07) were also mostly positive and larger than species with a small $\mathrm{PrV}$ (median -0.14, mean -0.19), however, there was no statistically significant effect found for $\operatorname{PrV}$ size $(p=0.087, \lambda=0.687)$. Migratory (median -0.06 , mean -0.01 ) and colonial (median 0.14 , mean 0.03) species and those that are flightless (median 0.00 , mean 0.07) and piscivorous (median -0.07, mean 0.02) also appeared to have larger OBs than the other species in their respective categories, however, there was also no statistically significant effect found for any of these categorizes (movement; $p=0.513, \lambda=0.887$, social structure; $p=0.253, \lambda=0.890$, flight capabilities; $p=0.359, \lambda=0.917$, diet; $p=0.308$, $\lambda=0.926)$.

To explore whether the size of other brain regions that process sensory information may be contributing to variations in the size of OBs, we used PGLS to test for correlations between the residuals of $\mathrm{OBs}$ and the $\mathrm{PrV}$ and $\mathrm{TeO}$. There is a significant

TABLE 1 | Scaling of the olfactory bulbs (OBs) with brain, telencephalon, and brainrest for nine avian orders.

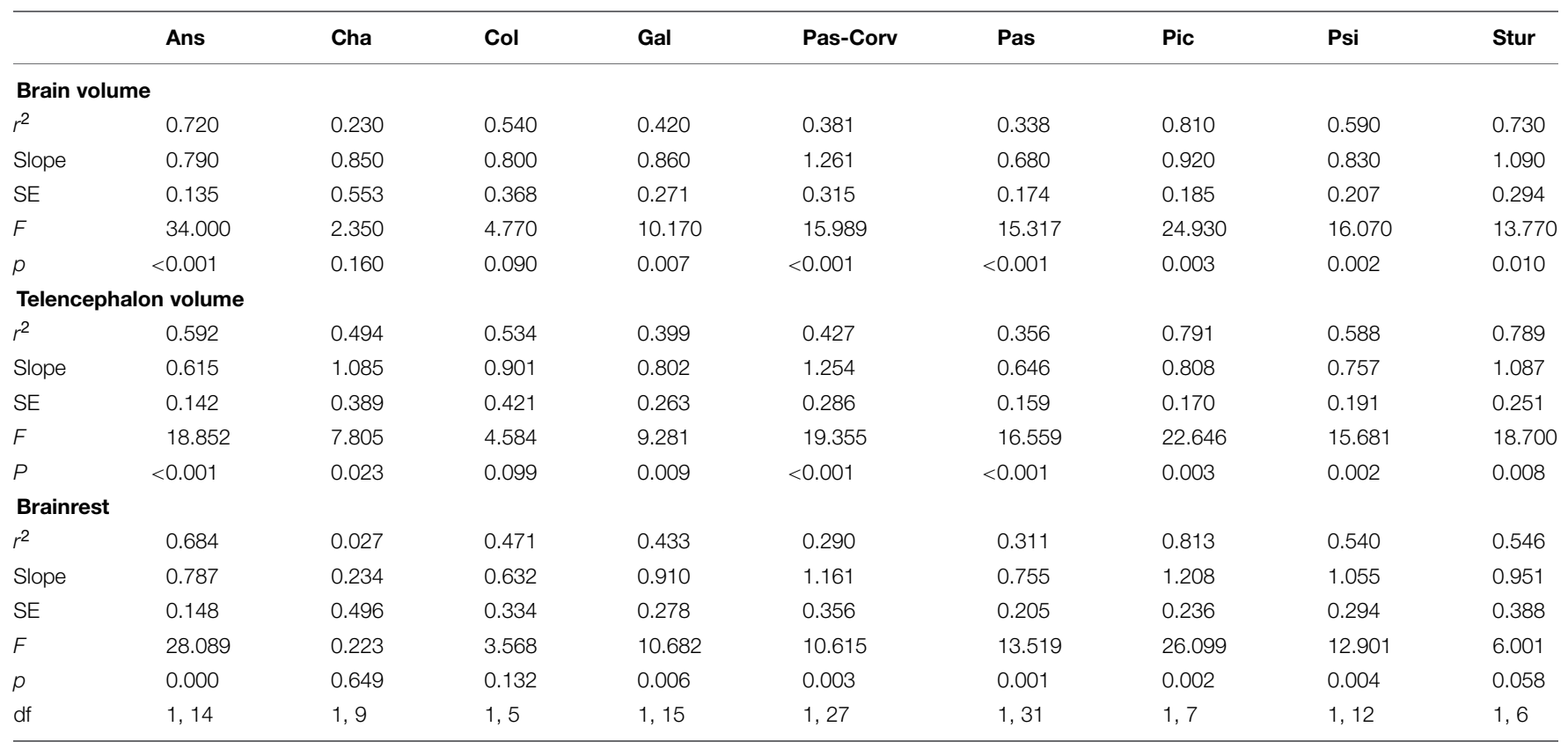

Data is shown for Anseriformes (Ans), Charadriiformes (Cha), Columbiformes (Col), Galliformes (Gal), Passeriformes, with (Pas) and without corvids and Cracticus tibicen (Pas-Corv), Piciformes (Pic), Psittaciformes (Psi) and Struthioniformes + Tinamiformes (Stur). 


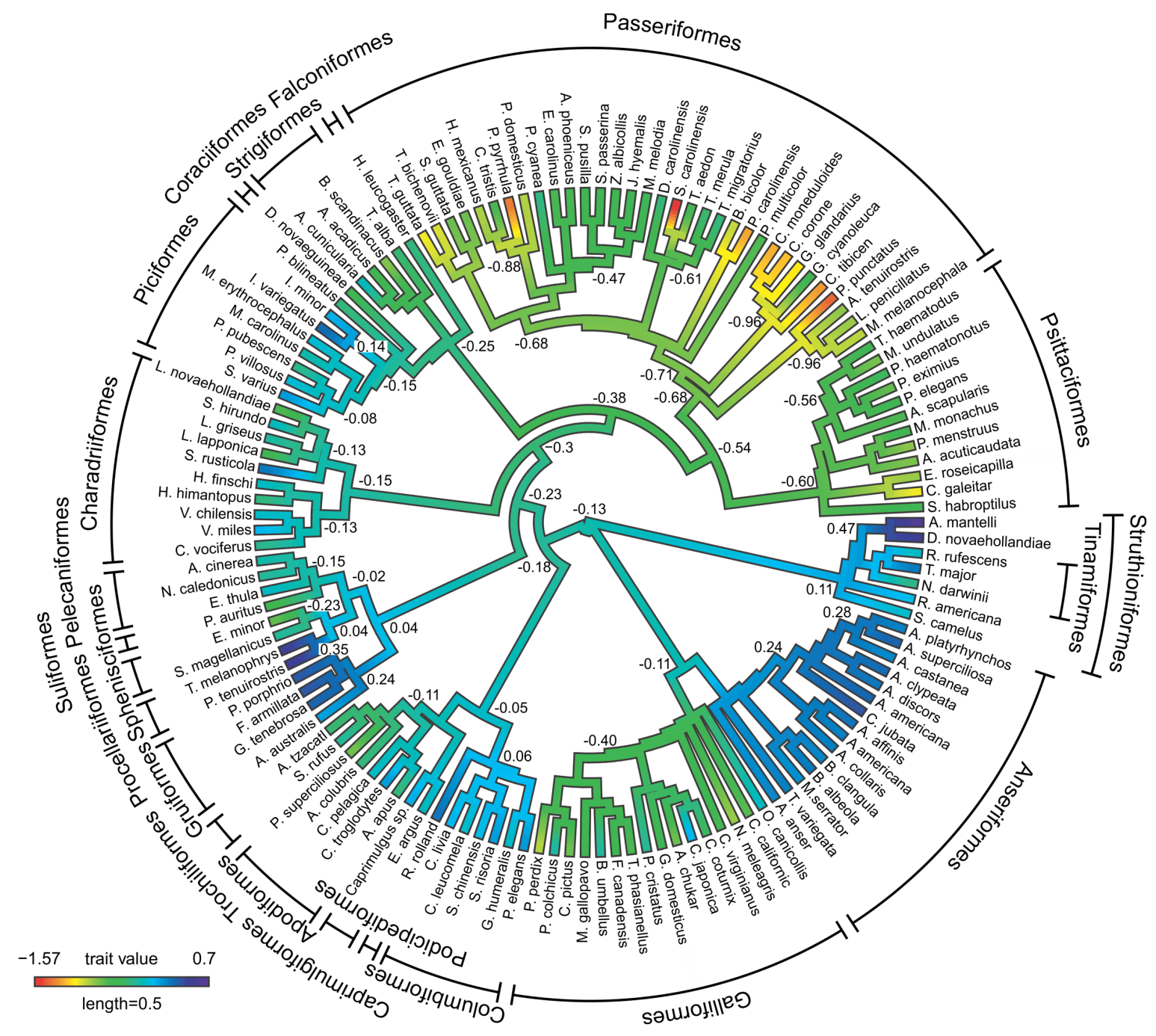

FIGURE 3 | Ancestral character estimates for OB volumes plotted onto an avian phylogeny. This method uses ancestral character estimation to visualize historical character states for OB volumes (plotted as a continuous trait) along the branches of a tree (see methods, Revell, 2013). The trait mapped was the relative size of OBs expressed as the residuals of the best fitting PGLS model of OBs against brain volume-OBs. The phylogeny is largely based on Hackett et al. (2008), with further resolution coming from other studies (see Materials and Methods). and negative correlation between the size of $\mathrm{TeO}$ and $\mathrm{PrV}$ ( $\alpha=-0.217 \pm 0.068, p=0.002$ ), suggesting that as one brain region increases in size the other decreases in size. No other significant correlations were found $(\mathrm{OB} / \mathrm{PrV}, \alpha=0.203 \pm 0.115$, $p=0.079$ or $\mathrm{OB} / \mathrm{TeO}, \alpha=-0.067 \pm 0.062, p=0.281)$, although there is some evidence to suggest a positive correlation between $\mathrm{OB}$ and PrV size, mostly driven by ducks, which have a large PrV and also large OBs (Figure 5). Ducks had both larger PrV and $\mathrm{OB}$ sizes compared to the closely related galliforms, whereas in galliforms the $\mathrm{TeO}$ was among the largest of any order. Parrots and songbirds had similar small $\mathrm{OB}$ sizes and an average $\mathrm{TeO}$, whereas parrots had a large PrV and songbirds a small PrV. Seabirds, rails and grebes all had large OBs and $\mathrm{TeO}$, whereas their PrV was small. No orders had obvious enlargements to all three brain regions.

\section{Discussion}

Overall, the size of avian OBs varies predominately with the size of the brain. This allometric relationship was for the most part isometric; the OBs gain volume at the same rate as the rest of the brain does, although there was some indication that the OBs gain volume faster than does the brain as a whole. A similar relationship has also been described in fish and some mammals, although there is a tendency for a negative allometic relationship; OBs gain mass slower than the rest of the brain (Gittleman, 1991; Yopak et al., 2015). Another feature of the OBs in mammals and fish is that they do not scale as tightly with brain size as other brain regions do and have a substantial level of allometric independence from the rest of the brain (Finlay and Darlington, 1995; Finlay et al., 2001; Reep et al., 


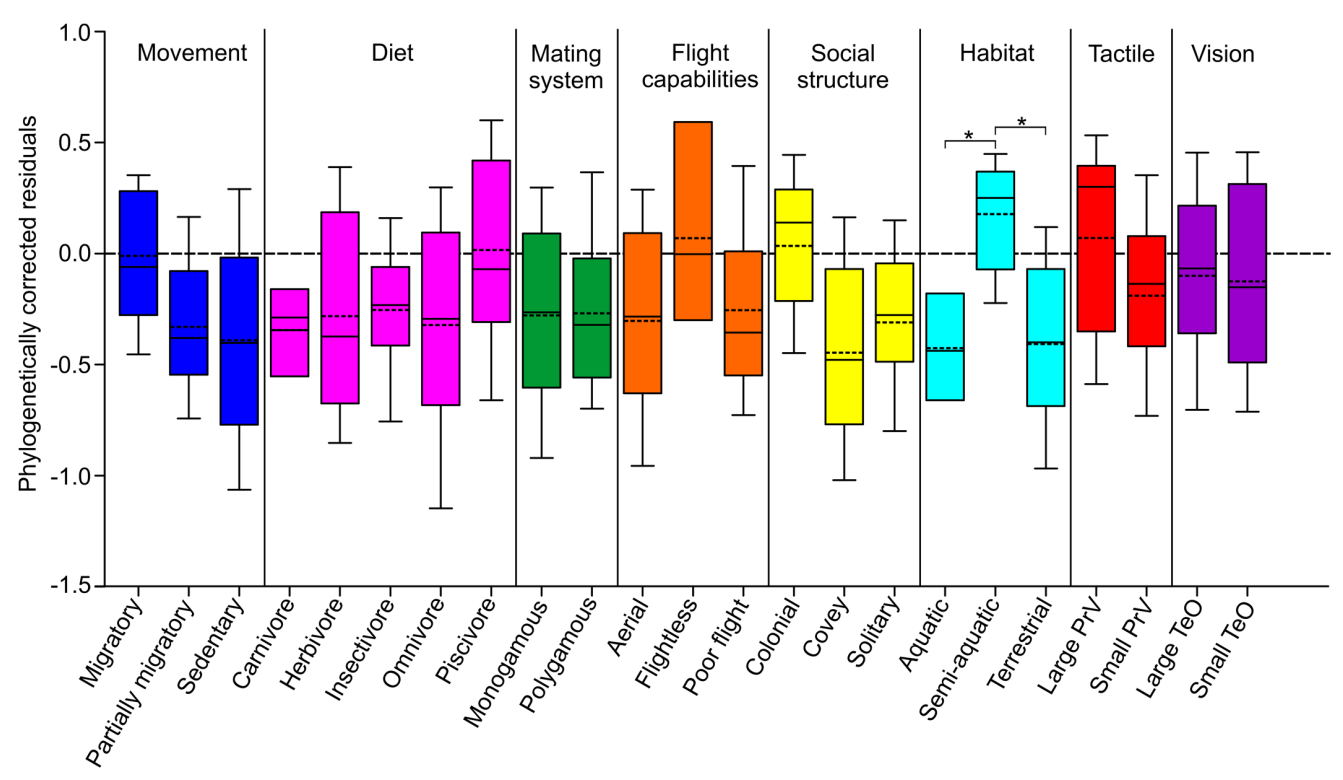

FIGURE 4 | Variation in OB sizes in relation to ecology and behavior. Box and whisker plots show the variation in $O B$ volumes among the different ecology and behavior categories, as calculated from phylogenetically corrected residuals. For each ecological niche category, the 'box' represents the second quartile and the error bars ('whiskers') are the first and third quartiles. The horizontal bar in each box represents the median, while the broken line indicates the mean. Asterisks indicate statistically significant differences $(p<0.05)$.
2007; Gonzalez-Voyer et al., 2009; Yopak et al., 2010, 2015). In birds too, not all of the variation in OB sizes can be explained by brain size alone with $r^{2}$ values that were between 0.58 and 0.64 and the data widely scattered. Interestingly, $r^{2}$ values for some mammals (Carnivora $=0.80$, primates $=0.56$, bats $=0.85$, insectivores = 0.83, Gittleman, 1991; Barton et al., 1995) and fish (GLS $=0.73$, PGLS $=0.69$, Yopak et al., 2015) are generally higher than we show in birds, indicating that in birds the size of OBs is less dependent on the size of the rest of the brain than it is in both mammals and fish. We suggest that much of this variation can be attributed to species differences in phylogeny, habitat, sensory ecology, and behavior, as is the case in mammals and fish (see below).

It should be noted that the study of Zelenitsky et al. (2011), which analyzed the OB ratios of Bang and Cobb (1968), showed that in birds the OBs are not correlated with body size and virtually none of the variation in $\mathrm{OB}$ sizes is explained by body size $\left(p=0.26, r^{2}=0.009\right)$. Why a significant correlation was not found in Zelenitsky et al. (2011) could reflect the fact that body size rather than brain size was used to examine allometric scaling, and also due to the methodological limitations of the Bang and Cobb data set (see Corfield et al., 2014; Caro et al., 2015). A study comparing the Bang and Cobb data set and the volumetric measurements obtained in the current study is indeed warranted to determine the validity of their methods.

Phylogenetic relationships and evolutionary history have undoubtedly been factors influencing the size of OBs in extant birds (see Figure 3). It is apparent that OBs in more basal species, including ratites, ducks, pigeons, rails, and seabirds are generally large, whereas OBs have been reduced in more diverged taxa, namely songbirds and parrots. Large OBs in these basal species have been inherited from early neornithines, where improved olfaction evolved for more effective foraging and/or navigation skills (Figure 3, Bang and Cobb, 1968; Wenzel, 1971; Zelenitsky et al., 2011). A shift away from olfaction has then occurred in more derived taxa during the evolution of visual and vestibular sensory enhancements association with flight (Wenzel, 1971; Alonso et al., 2004; Milner and Walsh, 2009). Probably the most interesting feature in the evolution of $\mathrm{OB}$ sizes across birds is in cases where sister taxa have diverged in OB sizes, namely between ducks and galliforms, penguins and seabirds, and honey guides and woodpeckers. In these cases it is clear that there have been opposing factors either driving the evolution of large or small OBs. In seabirds and honey guides, foraging based on olfactory cues has likely led to large OBs compared to their sister groups, which forage using visual and tactile cues (see below, Isack and Reyer, 1989; Nevitt, 1999; Short and Horne, 2001; del Hoyo et al., 2014). What evolutionary mechanisms have led to small OBs in galliforms is not obvious, however, in ducks large OBs may have evolved to utilize olfactory cues in a semi-aquatic environment (see below). In addition to differences between taxa, there are also many instances where a single species within a taxa stands out as having either small or large OBs, such as the small OBs in spotted pardalotes and the large OBs in Eurasian woodcocks. Such diversification in OBs size both among and within taxa suggests that olfaction is highly adaptable, with increases and decreases in olfactory capabilities evolving to meet the specific sensory demands of an ecological niche or a certain behavior.

Of all of the ecological/behavioral variables that we tested, only habitat was significant; semi-aquatic species had significantly larger OBs than terrestrial or aquatic species. Although a semiaquatic habitat is a broad definition and indeed encompasses 


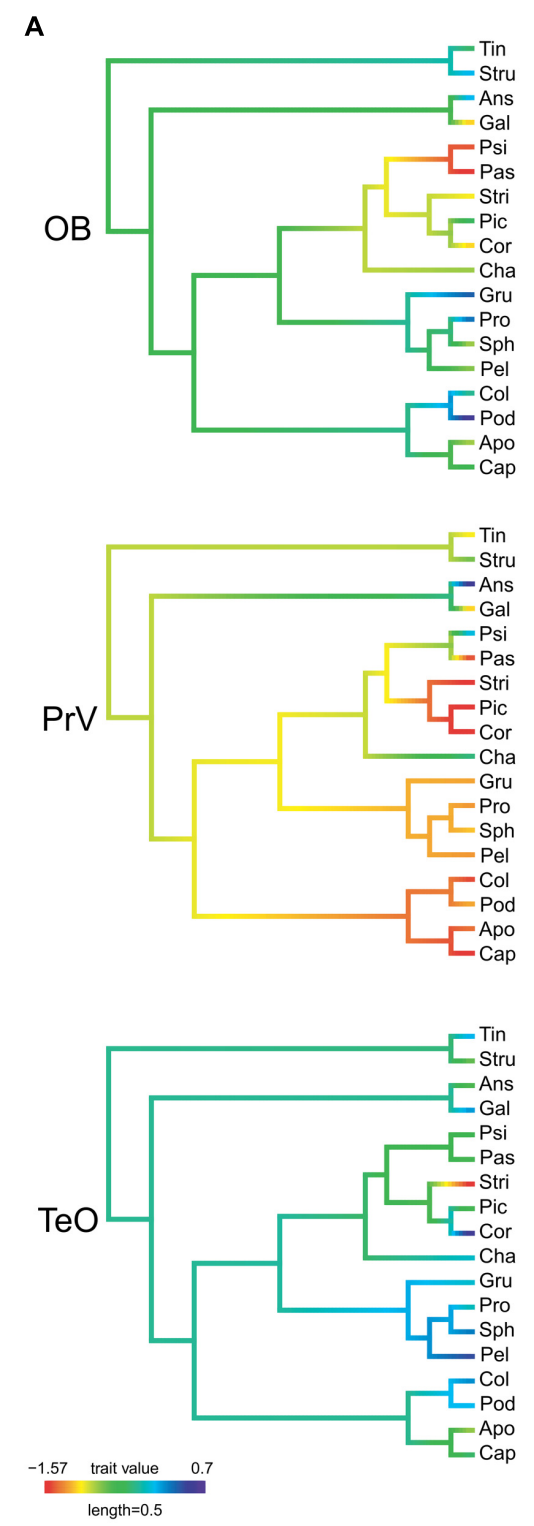

FIGURE 5 | Ancestral character estimates and residual plots for the OBs, the principal sensory nucleus of the trigeminal nerve (PrV), and the optic tectum (TeO). (A) Ancestral character estimates are plotted using the order averages for the relative size (expressed as the residuals of the best fitting PGLS model of each area against brain volume) of each sensory area (OB, PrV,
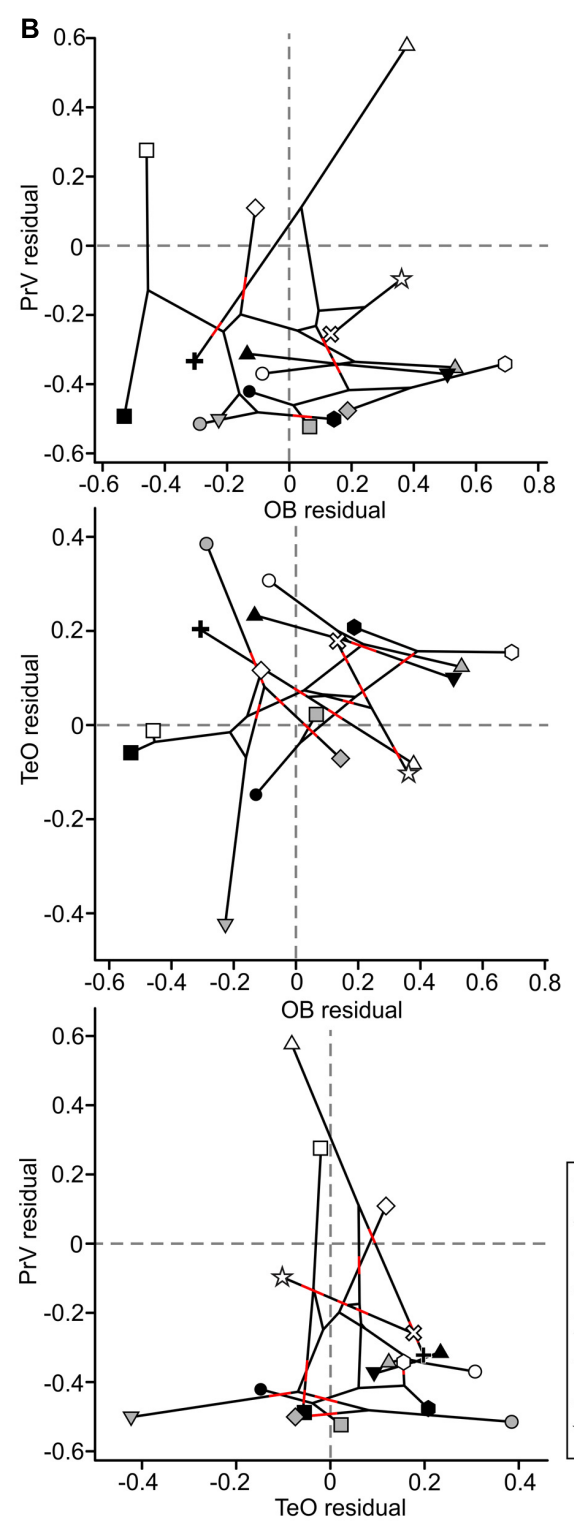

habitats ranging from rivers, lakes, oceans and wetlands, these habitats may provide olfactory cues that are particularly important for the birds that occupy them. Petrels, albatross, and prions, for example, can detect and localize high prey abundance using the odors (dimethyl sulfide and pyrazines) produced by phytoplankton when grazed by zooplankton as they forage out at sea (e.g., Grubb, 1972; Hutchison and Wenzel, 1980; Nevitt et al., 1995; Nevitt, 2000; Nevitt and Haberman, 2003; Nevitt and Bonadonna, 2005; Bonadonna et al., 2006; Dell'Ariccia and Bonadonna, 2013). The same likely applies to other semi-aquatic and also aquatic species, however, to date this has only been and $\mathrm{TeO}$ ) and are mapped onto the phylogeny based on Hackett et al. (2008). (B) Plots showing each sensory area plotting against the other while indicating the phylogenetic relationship of species (black lines). Red lines have been added to areas where the lines cross to allow for the tree branches to be more easily identified. shown in penguins (Spheniscidae), which use dimethyl sulfide as a behavioral cue to track upwind plankton blooms over long distances (Culik, 2001; Cunningham et al., 2008; Wright et al., 2011).

Interestingly, large relative OBs are not generally found in semi-aquatic mammals and instead have smaller relative OBs compared to terrestrial mammals (see review Pihlström, 2008). Relatively small OBs are found in otters (Mustelidae, Radinsky, 1968; Gittleman, 1991), aquatic insectivores (SánchezVillagra and Asher, 2002), pinnipeds (Repenning, 1976; Reep et al., 2007) and also platypus (Ornithorhynchus anatinus) 
(Pirlot and Nelson, 1978). Because early tetrapods evolved a new set of olfactory receptor molecules that were adapted to detecting airborne odors, mammals that moved back to an aquatic environment lacked the ability to detect scents underwater (Freitag et al., 1995, 1998). Therefore in mammals, the use of olfaction in semi-aquatic and aquatic habitats is limited and indeed in some aquatic mammals, such as toothed whales (Odontocetes), OBs and nerves are essentially absent or greatly reduced (Edinger, 1955; Breathnach, 1960; Morgane and Jacobs, 1972; Pirlot and Kamiya, 1985; Cave, 1988; Ridgway, 1990; Oelschlager and Kemp, 1998; Manger, 2006). Birds too are constrained by an ancestor that was adapted to detecting airborne odors, and indeed species that are aquatic and forage exclusively underwater, such as penguins and cormorants, have some of the smallest relative OBs, second only to songbirds (Figure 2). In these species, the opening of the external nares are reduced, functionally closed or an epithelial nasal valve is present. Although this is a necessary adaptation for diving underwater, it greatly reduces airflow to the caudal nasal concha (Bang, 1971; Bang and Wenzel, 1985). An exception to this is, however, found in shearwater and diving ducks, which do not have reduced OBs, yet forage almost exclusively by diving.

Given that semi-aquatic mammals and both aquatic mammals and birds have poor olfactory capabilities, why then do many semi-aquatic birds have a good sense of smell? Certain aspects of the behavioral ecology of birds, such as flight, have undoubtedly allowed some birds to evolve chemosensitive adaptations to take advantage of the olfactory cues in a semi-aquatic environment. Indeed, in some semi-aquatic species an enlargement to the olfactory system most certainly is a functional adaptation associated with this habitat, providing cues for navigation (Jacobs, 2012) and foraging in an otherwise featureless environment. The link between large relative $O B$ s and a semi-aquatic environment is hard to pinpoint in other species, including ducks, rails and shorebirds. Indeed, based on the foraging behavior in these species, and also the patterns observed in mammals, it would be predicted that they would have small OBs. One possibility is that large OBs have not been driven solely by occupying a semi-aquatic habitat, but are also due to a combination of other behaviors. For example in ducks, olfaction is utilized to determine endocrine condition (Balthazart and Schoffeniels, 1979; Jacob et al., 1979; Balthazart and Taziaux, 2009; Caro and Balthazart, 2010), could be used for determining hierarchical status when in colonials (Balthazart and Taziaux, 2009; Caro and Balthazart, 2010; Caro et al., 2015) or could be used to decode and map patterns of odorants for long range migration (Jacobs, 2012).

In addition to neural scaling, phylogeny and ecology/behavior, competition for brain space is another factor that is possibly causing variations in OB sizes among birds. Strong evidence of an apparent tradeoff, where the size of the OBs is negativity or positively correlated with the size of the $\mathrm{PrV}$ or $\mathrm{TeO}$ was

\section{References}

Alma, S., and Bee De Speroni, N. (1992). Indices cerebrales y composicion cuantativa encefalica en Athene cunicularia y Tyto alba. Facenas 9, 19-37. not found in birds. However, there were instances of small OBs in species with a large $\mathrm{TeO}$ and/or PrV. For example, parrots have one of the largest PrV sizes of any bird and also some of the smallest OBs, possibly indicating that increased beak sensitivities (Gutierrez-Ibanez et al., 2009; Demery et al., 2011) have led to reduced olfactory capabilities. As noted by Zelenitsky et al. (2011), the small OBs in parrots and also corvids could have also resulted from the extra neural demands associated with their increased cognitive abilities (Emery, 2006). We do, however, show a significant correlation between the size of PrV and $\mathrm{TeO}$, suggesting that species with large $\mathrm{PrV}$ have small $\mathrm{TeO}$ and vise versa. This was particularly true in shorebirds, where this neural trade off can be seen in difference in feeding ecology; some species rely mostly on vision whereas others locate food with a tactile organ in their beak tips (Piersma, 2011; Cunningham et al., 2013). Therefore in birds, it is likely that neural structures do compete for brain space, although OBs do appear to be more free to vary in size irrespective of the size of other sensory structures, which is also true in fish (Yopak et al., 2010, 2015).

Overall, in birds it is clear that many factors have led to the diversity in $\mathrm{OB}$ sizes in birds. On the one hand, overall brain size is an important factor in shaping the size of the OBs and so too is an evolutionary history that points to an ancestor with large OBs. On the other hand, habitat and behaviors such as migration, foraging strategies, and social structure are playing a role in driving enhancements to the olfactory system. In addition, the relative importance of other sensory regions needs to be considered as there is competition for a limited amount of brain space. It can therefore be concluded that multiple factors have in some way contributed to the diversity in OB sizes seen across birds and that it is important to consider all of these variables before we can fully understand the mechanisms driving the evolution of olfaction. By examining the $\mathrm{OB}$ sizes across such a diverse array of avian species we have helped to confirm that olfaction is indeed a functional sense in birds.

\section{Acknowledgments}

Funding for this study was provided by Natural Sciences and Engineering Research Council of Canada (NSERC) Discovery Grant (372237) and Accelerator Supplement (380284-2009) to $\mathrm{AI}$, and NSERC grants to DW.

\section{Supplementary Material}

The Supplementary Material for this article can be found online at: http://journal.frontiersin.org/article/10.3389/fnana. 2015.00102 
secretion in starlings. J. Anim. Ecol. 81, 605-613. doi: 10.1111/j.1365-2656.2011. 01940.x

Amo, L., Galvan, I., Tomas, G., and Sanz, J. J. (2008). Predator odour recognition and avoidance in a songbird. Funct. Ecol. 22, 289-293. doi: 10.1111/j.13652435.2007.01361.x

Amo, L., Visser, M. E., and Van Oers, K. (2011). Smelling out predators is innate in birds. Ardea 99, 177-184. doi: 10.5253/078.099.0207

Balthazart, J., and Schoffeniels, E. (1979). Pheromones are involved in the control of sexual behaviour in birds. Naturwissenschaften 66, 55-56. doi: 10.1007/BF00369365

Balthazart, J., and Taziaux, M. (2009). The underestimated role of olfaction in avian reproduction? Behav. Brain. Res. 200, 248-259. doi: 10.1016/j.bbr.2008.08.036

Bang, B. G. (1971). Functional anatomy of the olfactory system in 23 orders of birds. Acta Anat. 79, 1-76. doi: 10.1159/isbn.978-3-31801866-0

Bang, B. G., and Cobb, S. (1968). Size of olfactory bulb in 108 species of birds. Auk 85, 55-61. doi: 10.2307/4083624

Bang, B. G., and Wenzel, B. M. (1985). "Nasal cavity and olfactory system," in Form and Function in Birds, eds A. S. King and J. Mclelland (London: Academic Press), 195-225.

Barton, R. A., Purvis, A., and Harvey, P. H. (1995). Evolutionary radiation of visual and olfactory brain systems in primates, bats and insectivores. Philos. Trans. $R$. Soc. Lond. B 348, 381-392. doi: 10.1098/rstb.1995.0076

Benvenuti, S., and Ranvaud, R. (2004). Olfaction and homing ability of pigeons raised in a tropical area of Brazil. J. Exp. Zool. 301A, 961-970. doi: 10.1002/jez.a.123

Bertelli, S., and Porzecanski, A. L. (2004). Tinamou (Tinamidae) systematics: a preliminary combined analysis of morphology and molecules. Ornitol. Neotrop. 15(Suppl.), 1-8.

Blaser, N., Guskov, S. I., Meskenaite, V., Kanevskyi, V. A., and Lipp, H. P. (2013). Altered orientation and flight paths of pigeons reared on gravity anomalies: a GPS tracking study. PLoS ONE 8:e77102. doi: 10.1371/journal.pone.0077102

Blomberg, S. P., Garland, T. Jr., and Ives, A. R. (2003). Testing for phylogenetic signal in comparative data: behavioral traits are more labile. Evolution 57, 717-745. doi: 10.1111/j.0014-3820.2003.tb 00285.x

Boire, D. (1989). Comparaison Quantitative De l'encéphale, De ses grandes Subdivisions et des Relais Visuels, Trijemeaux et Acoustiques chez 28 Espèces d'oiseaux. Ph.D., thesis, Université de Montréal, Montréal, QC.

Bonadonna, F., Caro, S. P., Jouventin, P., and Nevitt, G. A. (2006). Evidence that blue petrel, Halobaena caerulea, fledglings can detect and orient to dimethyl sulfide. J. Exp. Biol. 209, 2165-2169. doi: 10.1242/jeb.02252

Bonadonna, F., and Nevitt, G. A. (2004). Partner-specific odor recognition in an Antarctic seabird. Science 306, 835. doi: 10.1126/science.1103001

Breathnach, A. S. (1960). The cetacean central nervous system. Biol. Rev. 35, 187-230. doi: 10.1111/j.1469-185X.1960.tb01414.x

Burish, M. J., Kueh, H. Y., and Wang, S. S. (2004). Brain architecture and social complexity in modern and ancient birds. Brain Behav. Evol. 63, 107-124. doi: 10.1159/000075674

Burnham, K. P., and Anderson, D. R. (2002). Model Selection and Multimodel Inference: A Practical Information-Theoretic Approach. New York: SpringerVerlag.

Buschhuter, D., Smitka, M., Puschmann, S., Gerber, J. C., Witt, M., Abolmaali, N. D., et al. (2008). Correlation between olfactory bulb volume and olfactory function. Neuroimage 42, 498-502. doi: 10.1016/j.neuroimage.2008.05.004

Carezzano, F. J., and Bee De Speroni, N. (1995). Composicion volumetrica encefalica e indices cerebrales en tres aves de ambiente acuatico (Ardeidae, Podicipedidae, Rallidae). Facena 11, 75-83.

Caro, S. P., and Balthazart, J. (2010). Pheromones in birds: myth or reality? J. Comp. Physiol. A 196, 751-766. doi: 10.1007/s00359-010-0534-4

Caro, S. P., Balthazart, J., and Bonadonna, F. (2015). The perfume of reproduction in birds: chemosignaling in avian social life. Horm. Behav. 68, 25-42. doi: 10.1016/j.yhbeh.2014.06.001

Castro, I., Cunningham, S. J., Gsell, A. C., Jaffe, K., Cabrera, A., and Liendo, C. (2010). Olfaction in birds: a closer look at the kiwi (Apterygidae). J. Avian Biol. 41, 213-218. doi: 10.1111/j.1600-048X.2010.05010.x

Cave, A. J. E. (1988). Note on olfactory activity in mysticetes. J. Zool. 214, 307-311. doi: 10.1111/j.1469-7998.1988.tb04724.x
Clark, L., Avilova, K. V., and Bean, N. J. (1993). Odor thresholds in passerines. Comp. Biochem. Physiol. A Comp. Physiol. 104, 305-312. doi: 10.1016/03009629(93)90322-U

Corfield, J. R., Birkhead, T. R., Spottiswoode, C. N., Iwaniuk, A. N., Boogert, N. J., Gutierrez-Ibanez, C., et al. (2012a). Brain size and morphology of the broodparasitic and cerophagous honeyguides (Aves: Piciformes). Brain Behav. Evol. 81, 170-186. doi: 10.1159/000348834

Corfield, J. R., Wild, J. M., Parsons, S., and Kubke, M. F. (2012b). Morphometric analysis of telencephalic structure in a variety of Neognath and Paleognath bird species reveals regional differences associated with specific behavioral traits. Brain Behav. Evol. 80, 181-195. doi: 10.1159/000339828

Corfield, J. R., Eisthen, H. L., Iwaniuk, A. N., and Parsons, S. (2014). Anatomical specialisations for enhanced olfactory sensitivity in kiwi, Apteryx mantelli. Brain Behav. Evol. 84, 214-226. doi: 10.1159/000365564

Corfield, J. R., Gsell, A. C., Brunton, D., Heesy, C. P., Hall, M. I., Acosta, M. L., et al. (2011). Anatomical specializations for nocturnality in a critically endangered parrot, the Kakapo (Strigops habroptilus). PLoS ONE 6:e22945. doi: 10.1371/journal.pone.0022945

Corfield, J. R., Long, B., Krilow, J. M., Wylie, D. R., and Iwaniuk, A. N. (2015). An uncoupling of the cellular scaling rules in the avian auditory system. Brain Struct. Funct. doi: 10.1007/s00429-015-1064-1 [Epub ahead of print].

Cramp, S. (1994). Handbook of the Birds of Europe, the Middle East and North Africa: The Birds of the Western Palearctic. Oxford: Oxford University Press.

Culik, B. (2001). Finding food in the open ocean: foraging strategies in Humboldt penguins. Zoology 104, 327-338. doi: 10.1078/0944-2006-00038

Cunningham, G. B., Strauss, V., and Ryan, P. G. (2008). African penguins (Spheniscus demersus) can detect dimethyl sulphide, a prey-related odour. J. Exp. Biol. 211, 3123-3127. doi: 10.1242/jeb.018325

Cunningham, S. J., Corfield, J. R., Iwaniuk, A. N., Castro, I., Alley, M. R., Birkhead, T. R., et al. (2013). The anatomy of the bill tip of kiwi and associated somatosensory regions of the brain: comparisons with shorebirds. PLOS ONE 8:e80036. doi: 10.1371/journal.pone.0080036

del Hoyo, J., Elliott, A., Sargatal, J., Christie, D. A., and De Juana, E. (2014). Handbook of the Birds of the World Alive [Online]. Barcelona: Lynx Edicions. Available at: http://www.hbw.com [Accessed 22 October, 2014].

Dell'Ariccia, G., and Bonadonna, F. (2013). Back home at night or out until morning? Nycthemeral variations in homing of anosmic Cory's shearwaters in a diurnal colony. J. Exp. Biol. 216, 1430-1433. doi: 10.1242/jeb.082826

Demery, Z. P., Chappell, J., and Martin, G. R. (2011). Vision, touch and object manipulation in Senegal parrots Poicephalus senegalus. Proc. Biol. Sci. 278, 3687-3693. doi: 10.1098/rspb.2011.0374

Donne-Gousse, C., Laudet, V., and Hanni, C. (2002). A molecular phylogeny of anseriformes based on mitochondrial DNA analysis. Mol. Phylogenet. Evol. 23, 339-356. doi: 10.1016/S1055-7903(02)00019-2

Dubbeldam, J. L. (1990). On the functional interpretation of quantitative differences in forebrain organization - the trigeminal and visualsystem in birds. Neth. J. Zool. 40, 241-253. doi: 10.1163/156854289X 00282

Dunbar, R. I. M. (1995). Neocortex size and group size in primates: a test of the hypothesis. J. Hum. Evol. 28, 287-296. doi: 10.1006/jhev.1995.1021

Duncan, R. P., Forsyth, D. M., and Hone, J. (2007). Testing the metabolic theory of ecology: allometric scaling exponents in mammals. Ecology 88, 324-333. doi: 10.1890/0012-9658(2007)88[324:TTMTOE]2.0.CO;2

Ebinger, P., and Lohmer, R. (1987). A volumetric comparison of brains between greylag geese (Anser anser L.) and domestic geese. J. Hirnforsch. 28, 291-299.

Edinger, T. (1955). Hearing and smell in cetacean history. Monatsschrift für Psychiatrie und Neurologie 129, 37-58. doi: 10.1159/000139733

Emery, N. J. (2006). Cognitive ornithology: the evolution of avian intelligence. Philos. Trans. R. Soc. Lond. B Biol. Sci. 361, 23-43. doi: 10.1098/rstb.2005.1736

Ericson, P. G. P., Jansén, A., Johansson, U. S., and Ekman, J. (2005). Intergeneric relationships of the crows, jays, magpies and allied groups (Aves: Corvidae) based on nucleotide sequence data. J. Avian Biol. 36, 222-234. doi: 10.1111/j.0908-8857.2001.03409.x

Felsenstein, J. (1985). Phylogenies and the comparative method. Am. Nat. 125, 1-15. doi: $10.1086 / 284325$

Fernandez, P., Carezzano, F., and Bee De Speroni, N. (1997). Analisis cuantitativo encefalico e indices cerebrales en Aratinga acuticaudata y Myiopsitta monachus de Argentina (Aves: Psittacidae). Rev. Chil. Hist. Nat. 70, 269-275. 
Fiaschi, V., Farina, A., and Ioalé, P. (1974). Homing experiments on swifts Apus apus (L.) deprived of olfactory perception. Ital. J. Zool. 8, 235-244.

Finlay, B. L., and Darlington, R. B. (1995). Linked regularities in the development and evolution of mammalian brains. Science 268, 1578-1584. doi: $10.1126 /$ science. 7777856

Finlay, B. L., Darlington, R. B., and Nicastro, N. (2001). Developmental structure in brain evolution. Behav. Brain Sci. 24, 263-278. doi: 10.1017/S0140525X01003958

Freitag, J., Krieger, J., Strotmann, J., and Breer, H. (1995). Two classes of olfactory receptors in Xenopus laevis. Neuron 15, 1383-1392. doi: 10.1016/08966273(95)90016-0

Freitag, J., Ludwig, G., Andreini, I., Rossler, P., and Breer, H. (1998). Olfactory receptors in aquatic and terrestrial vertebrates. J. Comp. Physiol. A 183, 635-650. doi: $10.1007 / \mathrm{s} 003590050287$

Gagliardo, A., Bried, J., Lambardi, P., Luschi, P., Wikelski, M., and Bonadonna, F. (2013). Oceanic navigation in Cory's shearwaters: evidence for a crucial role of olfactory cues for homing after displacement. J. Exp. Biol. 216, 2798-2805. doi: 10.1242/jeb.085738

Garland, T. Jr., Bennett, A. F., and Rezende, E. L. (2005). Phylogenetic approaches in comparative physiology. J. Exp. Biol. 208, 3015-3035. doi: 10.1242/jeb.01745

Garland, T. J., Harvey, P. H., and Ives, A. R. (1992). Procedures for the analysis of comparative data using phylogenetically independent contrasts. Systematic Biol. 41, 18-32. doi: 10.1093/sysbio/41.1.18

Garland, T. Jr., and Ives, A. R. (2000). Using the past to predict the present: confidence intervals for regression equations in phylogenetic comparative methods. Am. Nat. 155, 346-364. doi: 10.1086/303327

Gittleman, J. L. (1991). Carnivore olfactory bulb size: allometry, phylogeny and ecology. J. Zool. 72, 225, 253. doi: 10.1111/j.1469-7998.1991.tb03815.x

Gonzalez-Voyer, A., Winberg, S., and Kolm, N. (2009). Brain structure evolution in a basal vertebrate clade: evidence from phylogenetic comparative analysis of cichlid fishes. BMC Evol. Biol. 9:238. doi: 10.1186/1471-2148-9-238

Gould, J. L. (2009). Animal navigation: a wake-up call for homing. Curr. Biol. 19, R338-R339. doi: 10.1016/j.cub.2009.03.001

Graves, G. R. (1992). The greater yellow-headed vulture (Cathartes melambrotus) locates food by olfaction. J. Raptor Res. 26, 38-39.

Grubb, T. C. Jr. (1972). Smell and foraging in shearwaters and petrels. Nature 237, 404-405. doi: 10.1038/237404a0

Gsell, A. C. (2012). The Ecology and Anatomy of Scent in the Critically Endangered Kakapo (Strigops habroptilus). Ph.D. thesis, Massey University, Auckland.

Gutierrez-Ibanez, C., Iwaniuk, A. N., Moore, B. A., Fernandez-Juricic, E., Corfield, J. R., Krilow, J. M., et al. (2014). Mosaic and concerted evolution in the visual system of birds. PLoS ONE 9:e90102. doi: 10.1371/journal.pone.0090102

Gutierrez-Ibanez, C., Iwaniuk, A. N., and Wylie, D. R. (2009). The independent evolution of the enlargement of the principal sensory nucleus of the trigeminal nerve in three different groups of birds. Brain Behav. Evol. 74, 280-294. doi: $10.1159 / 000270904$

Hackett, S. J., Kimball, R. T., Reddy, S., Bowie, R. C., Braun, E. L., Braun, M. J., et al. (2008). A phylogenomic study of birds reveals their evolutionary history. Science 320, 1763-1768. doi: 10.1126/science.1157704

Hagelin, J. C. (2004). Observations on the olfactory ability of the Kakapo Strigops habroptilus, the critically endangered parrot of N. Z. Ibis 146, 161-164. doi: 10.1111/j.1474-919X.2004.00212.x

Hagelin, J. C. (2007). "Odors and chemical signaling," in Reproductive Biology and Phylogeny of Birds, ed. B. G. M. Jamieson (Jersey Plymouth: Science Publishers, Enfield NH), 75-119.

Hagelin, J. C., Jones, I. L., and Rasmussen, L. E. L. (2003). A tangerine- scented social odour in a monogamous seabird. Proc. Biol. Sci. 270, 1323-1329. doi: $10.1098 / \mathrm{rspb} .2003 .2379$

Hammock, J. (2005). Structure, Function and Context: the Impact of Morphometry and Ecology on Olfactory Sensitivity. Ph.D. thesis, Massachusetts Institutie of Technology, Cambridge, MA. doi: 10.1575/1912/1578

Harvey, P. H., and Pagel, M. D. (1991). The Comparative Method in Evolutionary Biology. Oxford: Oxford University Press.

Healy, S., and Guilford, T. (1990). Olfactory bulb size and nocturnality in birds. Evolution 44, 339-346. doi: 10.2307/2409412

Herculano-Houzel, S. (2009). The human brain in numbers: a linearly scaled-up primate brain. Front. Hum. Neurosci. 3:31. doi: 10.3389/neuro.09.031.2009
Herculano-Houzel, S., Avelino-De-Souza, K., Neves, K., Porfirio, J., Messeder, D., Feijo, L. M., et al. (2014). The elephant brain in numbers. front. Neuroanat. 8:46. doi: 10.3389/Fnana.2014.00046.

Holland, R. A., Thorup, K., Gagliardo, A., Bisson, I. A., Knecht, E., Mizrahi, D., et al. (2009). Testing the role of sensory systems in the migratory heading of a songbird. J. Exp. Biol. 212, 4065-4071. doi: 10.1242/jeb.034504

Hunt, S. P., and Webster, K. E. (1975). The projection of the retina upon the optic tectum of the pigeon. J. Comp. Neurol. 162, 433-445. doi: $10.1002 /$ cne. 901620403

Hutchison, L. V., and Wenzel, B. M. (1980). Olfactory guidance in foraging by procellariiforms. Condor 82, 314-319. doi: 10.2307/1367400

Isack, H. A., and Reyer, H. U. (1989). Honeyguides and honey gatherers: interspecific communication in a symbiotic relationship. Science 243, 13431346. doi: 10.1126/science.243.4896.1343

Iwaniuk, A. N., Clayton, D. H., and Wylie, D. R. W. (2006). Echolocation, vocal learning, auditory localization and the relative size of the avian auditory midbrain nucleus (MLd). Behav. Brain Res. 167, 305-317. doi: 10.1016/j.bbr.2005.09.015

Iwaniuk, A. N., Heesy, C. P., Hall, M. I., and Wylie, D. R. (2008). Relative Wulst volume is correlated with orbit orientation and binocular visual field in birds. J. Comp. Physiol. A 194, 267-282. doi: 10.1007/s00359-007-0304-0

Jacob, J., Balthazart, J., and Schoffeniels, E. (1979). Sex differences in the chemical composition of uropygial glandwaxes in domestic ducks. Biochem. Syst. Ecol. 7 , 149-153. doi: 10.1016/0305-1978(79)90024-3

Jacobs, L. F. (2012). From chemotaxis to the cognitive map: the function of olfaction. Proc. Natl. Acad. Sci. U.S.A. 109(Suppl. 1), 10693-10700. doi: $10.1073 /$ pnas. 1201880109

Jerison, H. J. (1973). Evolution of the Brain and Intelligence. New York: Academic Press.

Johansson, U. S., Fjeldsa, J., and Bowie, R. C. (2008). Phylogenetic relationships within Passerida (Aves: Passeriformes): a review and a new molecular phylogeny based on three nuclear intron markers. Mol. Phylogenet. Evol. 48, 858-876. doi: 10.1016/j.ympev.2008.05.029

Jorge, P. E., Marques, A. E., and Phillips, J. B. (2009). Activational rather than navigational effects of odors on homing of young pigeons. Curr. Biol. 19, 650-654. doi: 10.1016/j.cub.2009.02.066

Jorge, P. E., Marques, P. A., and Phillips, J. B. (2010). Activational effects of odours on avian navigation. Proc. Biol. Sci. 277, 45-49. doi: 10.1098/rspb.2009.1521

Kubke, M. F., Massoglia, D. P., and Carr, C. E. (2004). Bigger brains or bigger nuclei? Regulating the size of auditory structures in birds. Brain Behav. Evol. 63, 169-180. doi: 10.1159/000076242

Lavin, S. R., Karasov, W. H., Ives, A. R., Middleton, K. M. and Garland, T. Jr. (2008). Morphometrics of the avian small intestine compared with that of nonflying mammals: a phylogenetic approach. Physiol. Biochem. Zool. 81, 526-550. doi: $10.1086 / 590395$

Lehmann, J., and Dunbar, R. I. M. (2009). Network cohesion, group size and neocortex size in female-bonded Old World primates. Proc. Biol. Sci. 276, 4417-4422. doi: 10.1098/rspb.2009.1409

Lequette, B., Verheyden, C., and Jouventin, P. (1989). Olfaction in subantarctic seabirds: its phylogenetic and ecological significance. Condor 91, 732-735. doi $10.2307 / 1368131$

Mackay-Sim, A., and Royet, J. P. (2006). "Structure and function of the olfactory system," in Olfaction and the brain, eds W. Brewer, D. Castle, and C. Pantelis (Cambridge: Cambridge University Press), 3-27.

Maddison, W. P., and Maddison, D. R. (2011). Mesquite: a Modular System for Evolutionary Analysis. Version 2.75. Available at: http://mesquiteproject.org [accessed November 12, 2013].

Manger, P. R. (2006). An examination of cetacean brain structure with a novel hypothesis correlating thermogenesis to the evolution of a big brain. Biol. Rev. Camb. Philos. Soc. 81, 293-338. doi: 10.1017/S1464793106 007019

Martin, G. R. (1994). Visual fields in woodcocks Scolopax rusticola (Scolopacidae; Charadriiformes). J. Comp. Physiol. A 174, 787-793. doi: 10.1007/BF00 192728

Martin, G. R., Wilson, K. J., Martin Wild, J., Parsons, S., Fabiana Kubke, M., and Corfield, J. (2007). Kiwi forego vision in the guidance of their nocturnal activities. PLoS ONE 2:e198. doi: 10.1371/journal.pone.0000198 
Mayr, G. (2011). The phylogeny of charadriiform birds (shorebirds and allies) reassessing the conflict between morphology and molecules. Zool. J. Linn. Soc. Lond. 161, 916-934. doi: 10.1111/j.1096-3642.2010.00654.x

Mehlhorn, J., Hunt, G. R., Gray, R. D., Rehkamper, G., and Gunturkun, O. (2010). Tool-making new Caledonian crows have large associative brain areas. Brain Behav. Evol. 75, 63-70. doi: 10.1159/000295151

Mihailova, M., Berg, M. L., Buchanan, K. L., and Bennett, A. T. D. (2014). Odour-based discrimination of subspecies, species and sexes in an avian species complex, the crimson rosella. Anim. Behav. 95, 155-164. doi: 10.1016/j.anbehav.2014.07.012

Milner, A. C., and Walsh, S. A. (2009). Avian brain evolution: new data from palaeogene birds (Lower Eocene) from England. Zool. J. Linn. Soc. 155, 198-219. doi: 10.1111/j.1096-3642.2008.00443.x

Morgane, P. J., and Jacobs, M. S. (1972). "Comparative anatomy of the cetacean nervous system," in Functional Anatomy of Marine Mammals, ed. R. J. Harrison (London: Academic Press), 117-244.

Nevitt, G. A. (1999). Olfactory foraging in Antarctic seabirds: a speciesspecific attraction to krill odors. Mar. Ecol. Prog. Ser. 177, 235-241. doi: $10.3354 /$ meps 177235

Nevitt, G. A. (2000). Olfactory foraging by Antarctic procellariiform seabirds: life at high Reynolds numbers. Biol. Bull. 196, 245-253. doi: 10.2307/1542527

Nevitt, G. A., and Bonadonna, F. (2005). Sensitivity to dimethyl sulphide suggests a mechanism for olfactory navigation by seabirds. Biol. Lett. 1, 303-305. doi: 10.1098/rsbl.2005.0350

Nevitt, G. A., and Haberman, K. (2003). Behavioral attraction of Leach's stormpetrels (Oceanodroma leucorrhoa) to dimethyl sulfide. J. Exp. Biol. 206, 14971501. doi: 10.1242/jeb.00287

Nevitt, G. A., Veit, R. R., and Kareiva, P. (1995). Dimethyl sulfide as a foraging clue for Antarctic procellariiform seabirds. Nature 376, 680-682. doi: 10.1038/376680ao

Oelschlager, H. H., and Kemp, B. (1998). Ontogenesis of the sperm whale brain. J. Comp. Neurol. 399, 210-228. doi: 10.1002/(SICI)10969861(19980921)399:2<210::AID-CNE5>3.0.CO;2-3

Pagel, M. (1999). Inferring the historical patterns of biological evolution. Nature 401, 877-884. doi: 10.1038/44766

Papi, F. (1976). The olfactory navigation system of the homing pigeon. Verh. Dtsch. Zool. Ges. 69, 184-205.

Papi, F. (1982). "Olfaction and homing in pigeons: ten years of experiments," in Avian Navigation, eds F. Papi and H. G. Wallraff (Berlin: Springer Verlag), 149-159.

Paradis, E., Claude, J., and Strimmer, K. (2004). APE: analyses of phylogenetics and evolution in R language. Bioinformatics 20, 289-290. doi: 10.1093/bioinformatics/btg412

Phillips, J. B., and Jorge, P. E. (2014). Olfactory navigation: failure to attempt replication of critical experiments keeps controversy alive. Reply to Wallraff. Anim. Behav. 90, e7-e9. doi: 10.1016/j.anbehav.2014.01.013

Piersma, T. (2011). From spoonbill to spoon-billed sandpiper: the perceptual dimensions to the niche. Ibis 153, 659-661. doi: 10.1111/j.1474-919X.2011.01170.x

Pihlström, H. (2008). "Comparative anatomy and physiology of chemical senses in aquatic mammals," in Sensory Evolution on the Threshold: Adaptations in Secondarily Aquatic Vertebrates, eds J. G. M. Thewissen and S. Nummela (Berkeley: University of California Press), 95-109.

Pinheiro, J., Bates, D., Debroy, S., Sarkar, D., and R-Core-Team. (2014). Nlme: Linear and Nonlinear Mixed Effects Models. R package version 3.1-118. Available at: http://CRAN.R-project.org/package=nlme.

Pirlot, P., and Kamiya, T. (1985). Qualitative and quantitative brain morphology in the sirenian Dugong dugong Erxl. J. Zoolog. Syst. Evol. Res. 23, 147-155. doi: 10.1111/j.1439-0469.1985.tb00577.x

Pirlot, P., and Nelson, J. (1978). Volumetric analyses of monotreme brains. Aust. Zool. 20, 171-179.

Pistone, E., Carezzano, F., and Bee De Speroni, N. (2002). Tamano relativo encefalico e indices cerebrales en Vanellus C. chilensis (Aves: Charadriidae). Rev. Chil. Hist. Nat. 75, 595-602. doi: 10.4067/S0716-078X2002000300010

Purvis, A., and Garland, T. Jr. (1993). Polytomies in comparative analyses of continuous characters. Systematic Biol. 42, 569-575. doi: 10.1093/sysbio/42.4.569
R Core Team. (2013). R: A Language and Environment for Statistical Computing. Available at: http://www.r-project.org/.

Radinsky, L. B. (1968). Evolution of somatic sensory specialization in otter brains. J. Comp. Neurol. 134, 495-506. doi: 10.1002/cne.901340408

Reep, R. L., Finlay, B. L., and Darlington, R. B. (2007). The limbic system in mammalian brain evolution. Brain Behav. Evol. 70, 57-70. doi: 10.1159/000101491

Rehkamper, G., Frahm, H. D., and Zilles, K. (1991). Quantitative development of brain and brain structures in birds (galliformes and passeriformes) compared to that in mammals (insectivores and primates). Brain Behav. Evol. 37, 125-143. doi: 10.1159/000114353

Repenning, C. A. (1976). Adaptive evolution of sea lions and walruses. Syst. Zool. 25, 375-390. doi: 10.2307/2412512

Revell, L. J. (2009). Size-correction and principal components for interspecific comparative studies. Evolution 63, 3258-3268. doi: 10.1111/j.1558-5646.2009.00804.x

Revell, L. J. (2012). phytools: an R package for phylogenetic comparative biology (and other things). Methods Ecol. Evol. 3, 217-223. doi: 10.1111/j.2041210X.2011.00169.x

Revell, L. J. (2013). Two new graphical methods for mapping trait evolution on phylogenies. Methods Ecol. Evol. 4, 754-759. doi: 10.1111/2041-210X.12066

Ribeiro, P. F., Manger, P. R., Catania, K. C., Kaas, J. H., and Herculano-Houzel, S. (2014). Greater addition of neurons to the olfactory bulb than to the cerebral cortex of eulipotyphlans but not rodents, afrotherians or primates. Front. Neuroanat. 8:23. doi: 10.3389/fnana.2014.00023

Ridgway, S. H. (1990). "The central nervous system of the bottlenose dolphin," in The Bottlenose Dolphin, eds S. Leatherwood and R. R. Reeves (New York: Academic Press), 69-97.

Roper, T. J. (1999). Olfaction in birds. Adv. Stud. Behav. 28, 247-332. doi: 10.1016/S0065-3454(08)60219-3

Roth, T. C., Cox, J. G., and Lima, S. L. (2008). Can foraging birds assess predation risk by scent. Anim. Behav. 76, 2021-2027. doi: 10.1016/j.anbehav.2008.08.022

Sánchez-Villagra, M. R., and Asher, R. J. (2002). Cranio-sensory adaptations in small faunivorous semiaquatic mammals, with special reference to olfaction and the trigeminal system. Mammalia 66, 93-109. doi: 10.1515/mamm.2002.66.1.93

Short, L. L., and Horne, J. F. M. (2001). Toucans, Barbets and Honeyguides. Oxford: Oxford University Press.

Smith, S. A., and Paselk, R. A. (1986). Olfactory sensitivity of the turkey vulture (Cathartes aura) to three carrion associated odorants. Auk 103, 586-592.

Snyder, G. K., and Peterson, T. T. (1979). Olfactory sensitivity in the blackbilled magpie and in the pigeon. Comp. Biochem. Physiol. 62, 921-925. doi: 10.1016/0300-9629(79)90029-X

Stager, K. E. (1964). The role of olfaction in food location by the turkey vulture (Cathartes aura). Los Angeles County Museum Contributions to Science. Wilson Bull. 76, 390-392.

Stanbury, M., and Briskie, J. V. (2015). I smell a rat: can New Zealand birds recognize the odor of an invasive mammalian predator? Curr. Zool. 61, 34-41.

Stattleman, A. J., Talbot, R. B., and Coulter, D. B. (1975). Olfactory thresholds of pigeon (Columba livia), quail (Colinus virginianus) and chickens (Gallus gallus). Comp. Biochem. Physiol. 50A, 807-809. doi: 10.1016/0300-9629(75)90148-6

Swanson, D. L., and Garland, T. Jr. (2009). The evolution of high summit metabolism and cold tolerance in birds and its impact on present-day distributions. Evolution 63, 184-194. doi: 10.1111/j.1558-5646.2008.00522.x

Verheyden, C., and Jouventin, P. (1994). Olfactory behavior of foraging procellariiforms. Auk 111, 285-291. doi: 10.2307/4088593

Waldvogel, J. A. (1989). Olfactory orientation by birds. Curr. Ornithol. 1, 269-321. doi: 10.1007/978-1-4757-9918-7_6

Walker, J. C., Walker, D. B., Tambiah, C. R., and Gilmore, K. S. (1986). Olfactory and non-olfactory odor detection in pigeons: elucidation by a cardiac acceleration paradigm. Physiol. Behav. 38, 575-580. doi: 10.1016/00319384(86)90428-2

Wallraff, H. G. (2003). Olfactory navigation by birds. J. Ornithol. 144, 1-32. doi: 10.1007/BF02465514

Wallraff, H. G. (2004). Avian olfactory navigation: its empirical foundation and conceptual state. Anim. Behav. 67, 189-204. doi: 10.1016/j.anbehav.2003.06.007

Wallraff, H. G. (2013). Ratios among atmospheric trace gases together with winds imply exploitable information for bird navigation: a model elucidating 
experimental results. Biogeosciences 10, 6929-6943. doi: 10.5194/bg-10-69292013

Wallraff, H. G. (2014). Do olfactory stimuli provide positional information for homeoriented avian navigation. Anim. Behav. 90, e1-e6. doi: 10.1016/j.anbehav.2014.01.012

Wallraff, H. G., Kiepenheuer, J., Neumann, M. F., and Streng, A. (1995). Homing experiments with starlings deprived of the sense of smell. Condor 97, 20-26. doi: $10.2307 / 1368979$

Wang, N., Kimball, R. T., Braun, E. L., Liang, B., and Zhang, Z. (2013). Assessing phylogenetic relationships among Galliformes: a multigene phylogeny with expanded taxon sampling in Phasianidae. PLoS ONE 8:e64312. doi: 10.1371/journal.pone.0064312

Wenzel, B. M. (1968). Olfactory prowess of the kiwi. Nature 220, 1133-1134. doi: $10.1038 / 2201133 \mathrm{a} 0$

Wenzel, B. M. (1971). Olfactory sensation in the kiwi and other birds. Ann. N. Y. Acad. Sci. 188, 183-193. doi: 10.1111/j.1749-6632.1971.tb13097.x

Whittaker, D. J., Gerlach, N. M., Soini, H. A., Novotny, M. V., and Ketterson, E. D. (2013). Bird odour predicts reproductive success. Anim. Behav. 86, 697-703. doi: 10.1016/j.anbehav.2013.07.025

Wiltschko, R. (2012). Navigation without technical aids: how pigeons find their way home. Eur. J. Nav. 10, 22-31.

Wiltschko, W., and Wiltschko, R. (1992). "Pigeon homing: the effect of temporary anosmia on orientation behavior," in Chemical Signals in Vertebrates, Vol. 6, eds R. L. Doty and D. Müller-Schwarze (New York: Plenum Press), 435-442.

Wright, K. L. B., Pichegru, L., and Ryan, P. G. (2011). Penguins are attracted to dimethyl sulphide at sea. J. Exp. Biol. 214, 2509-2511. doi: 10.1242/jeb.058230

Wright, T. F., Schirtzinger, E. E., Matsumoto, T., Eberhard, J. R., Graves, G. R., Sanchez, J. J., et al. (2008). A multilocus molecular phylogeny of the parrots
(Psittaciformes): support for a Gondwanan origin during the cretaceous. Mol. Biol. Evol. 25, 2141-2156. doi: 10.1093/molbev/msn 160

Yopak, K. E., Lisney, T. J., and Collin, S. P. (2015). Not all sharks are "swimming noses": variation in olfactory bulb size in cartilaginous fishes. Brain Struct. Funct. 220, 1127-1143. doi: 10.1007/s00429-0140705-0

Yopak, K. E., Lisney, T. J., Darlington, R. B., Collin, S. P., Montgomery, J. C., and Finlay, B. L. (2010). A conserved pattern of brain scaling from sharks to primates. Proc. Natl. Acad. Sci. U.S.A. 107, 12946-12951. doi: 10.1073/pnas.1002195107

Zelenitsky, D. K., Therrien, F., Ridgely, R. C., Mcgee, A. R., and Witmer, L. M. (2011). Evolution of olfaction in non-avian theropod dinosaurs and birds. Proc. Biol. Sci. 278, 3625-3634. doi: 10.1098/rspb.2011.0238

Zidar, J., and Lovlie, H. (2012). Scent of the enemy: behavioural responses to predator faecal odour in the fowl. Anim. Behav. 84, 547-554. doi: 10.1016/j.anbehav.2012.06.006

Conflict of Interest Statement: The authors declare that the research was conducted in the absence of any commercial or financial relationships that could be construed as a potential conflict of interest.

Copyright (c) 2015 Corfield, Price, Iwaniuk, Gutiérrez-Ibáñez, Birkhead and Wylie. This is an open-access article distributed under the terms of the Creative Commons Attribution License (CC BY). The use, distribution or reproduction in other forums is permitted, provided the original author(s) or licensor are credited and that the original publication in this journal is cited, in accordance with accepted academic practice. No use, distribution or reproduction is permitted which does not comply with these terms. 